\title{
Potencialidad de uso de aguas servidas para riego y recarga de acuíferos: cuenca del río La Villa, República de Panamá
}

\section{Potential use of wastewater for irrigation and aquifer recharge water: La Villa River basin, Republic of Panamá}

\author{
Valentina Opolenko ${ }^{1}$ \\ Centro del Agua del Trópico Húmedo para \\ América Latina y el Caribe (CATHALAC), Panamá
}

\begin{abstract}
Resumen
Ante la demanda creciente de los recursos hídricos en Panamá, las aguas residuales pueden constituir una opción fiable como fuente de abastecimiento para distintos usos, especialmente en situaciones de escasez. El objetivo de esta investigación fue evaluar la sostenibilidad y viabilidad de riego y técnicas de recarga artificial de acuíferos en la parte baja de la cuenca del río La Villa mediante el aprovechamiento de aguas residuales tratadas procedentes de la PTAR de Chitré, para su posterior recuperación por procesos naturales y uso como fuente alternativa de agua. La metodología que se aplicó tuvo sus fundamentos en un análisis multidisciplinario a través de un diagnóstico biofísico y socioeconómico. Se evaluó la posibilidad de implementación de soluciones tecnológicas como la reutilización directa con fines de riego de aguas depuradas en humedales y recarga superficial de acuíferos de manera indirecta por infiltración de excedentes de riego. Los resultados de los estudios técnicos permitieron establecer el nivel de remoción en humedales de contaminantes del agua postratada con la ayuda del sustrato y vegetación seleccionada. Además, se logró con la realización de los estudios geológicos e hidrogeológicos generar un bloque modelo inédito de la disposición espacial de capas litológicas y estimar sus volúmenes, definiendo así la zona acuífera capaz de recibir por infiltración el agua de recarga, almacenarla y, posteriormente, entregarla para hacer buen uso de ella.
\end{abstract}

Palabras clave: Cuenca hidrográfica, agua subterránea, recarga acuífera, agua residual, humedal.

1 Doctora en Tecnología Ambiental y Gestión del Agua. Investigadora en Gestión del Agua del Centro del Agua del Trópico Húmedo para América Latina y el Caribe, CATHALAC, Edificio 111, Ciudad del Saber, Clayton, Panamá, República de Panamá. Correo electrónico: valentina.opolenko@cathalac.int iD: https:// orcid.org/0000-0002-8734-9349 


\begin{abstract}
Given the growing demand for water resources in Panama, wastewater can be a reliable option as a source of supply for various uses, especially in scarcity situations. The objective of this research was to evaluate the sustainability and viability of irrigation and artificial recharge techniques of aquifers in the lower part of the La Villa River basin, using treated wastewater coming from the Chitre PTAR, for its subsequent recovery by natural processes and use as an alternative water source. The methodology applied had its foundations in a multidisciplinary analysis through a biophysical and socioeconomic diagnosis. The possibility of implementing technological solutions like the direct reuse with irrigation purposes of water treated in wetlands and of superficial indirect recharge by infiltration of irrigation surpluses was evaluated. The results of the technical studies established the levels of removal of contaminants in wetlands post-treated water with the help of the substrate and selected vegetation. In addition, it was possible to carry out geologic and hydrogeologic studies, to generate an unprecedented model block of the spatial disposition of lithological layers and to estimate their volumes, therefore defining the aquifer zone capable of receiving by infiltration the recharge water, to store it and afterwards yielding it for good use.
\end{abstract}

Keywords: Hydrographic basin; groundwater; aquifer recharge; wastewater; wetland.

\title{
Introducción
}

Los cambios profundos que se han producido en el planeta como consecuencia de la revolución en el conocimiento científico y tecnológico han impactado de manera directa en nuestro modo de vida, en el medioambiente, así como en la disponibilidad de los recursos hídricos. A medida que aumenta la escasez de agua y la variabilidad hidrológica es mayor, afrontar los cambios provocados por el desarrollo constituye un desafío extraordinario debido a enormes presiones, riesgos y conflictos que surgen por el uso de recursos hídricos.

La República de Panamá, como la mayoría de los países centroamericanos, comparte un ambiente caracterizado por una aparente abundancia de agua, aunque esta se encuentra distribuida en forma muy desigual tanto espacial como temporalmente. En las últimas décadas, esta visión del agua ha llevado a un patrón de extracción que no contempla el uso racional del recurso, su conservación, la preservación de las cuencas, ni las necesidades de otros grupos de población en condiciones más vulnerables. Como consecuencia de este patrón de explotación, las fuentes de agua abundantes en alguna época se están extinguiendo paulatinamente. Además, algunas de ellas se encuentran contaminadas. Según los datos de MIAMBIENTE (2019), la demanda total de agua en Panamá en 2018 alcanzó un volumen de $41,899 \mathrm{~mm}^{3}$, lo que representa un $33 \%$ de la oferta hídrica promedio el periodo 2000-2018, y este aumento de la demanda de 
agua está relacionado de forma importante con el crecimiento económico y poblacional que experimenta el país. En cuanto a la calidad de las fuentes hídricas superficiales en función al Índice de Calidad de Agua (ICA), se puede indicar que, del total de 102 puntos de muestreo a nivel nacional (26 de las 52 cuencas hidrográficas del país), el 65\% presenta calidad de agua aceptable y el $35 \%$ son aguas con distintos grados de contaminación (Cornejo et al., 2017). Por lo tanto, a causa de las distintas actividades antropogénicas que contribuyen al desmejoramiento de la calidad del agua en las cuencas hidrográficas, así como la subvaloración del recurso hídrico al considerar la mayoría de los panameños que el agua es un recurso infinito cuyo derecho de uso es público (es decir, que se asume que el agua no tiene costo alguno) y la existente debilidad de los sistemas de supervisión, control y fiscalización del recurso hídrico, la disponibilidad de este recurso natural en el país ha sido afectada mientras la demanda se incrementa (ANAM, 2011).

Conforme a lo anterior, debido a todos estos factores, la competencia entre individuos y entre distintos sectores por este recurso esencial está aumentando de manera constante. Sin duda, la agricultura es y seguirá siendo el sector clave para el manejo del agua y también para mantener la seguridad alimentaria. Siendo el sector agropecuario panameño uno de los mayores usuarios del agua, tiene un reto de desarrollo sostenible en su doble dimensión: por un lado, la de satisfacer las necesidades humanas y, por el otro, la de mantener la integridad de los ecosistemas, conjugando ambos objetivos. Entretanto en este reto, el suministro de agua potable y la gestión de las aguas residuales son componentes del saneamiento ambiental que definen la gestión de sostenibilidad del recurso hídrico y deben evaluarse de forma integral, con miras a resolver la problemática de escasez hídrica de las urbes de hoy. Según las Naciones Unidas, en el año 2050 se prevé que cerca del $70 \%$ de la población mundial vivirá en ciudades, en comparación con el 50\% actual (UN, 2014). En la mayoría de las ciudades de los países desarrollados existe infraestructura y recursos adecuados para abordar la gestión de las aguas residuales de manera eficiente. Las oportunidades de aprovecharlas como un recurso valioso son enormes y la gestión de estas será una fuente asequible y sostenible de agua, energía, nutrientes y otros materiales recuperables. 
La reutilización en agricultura de las aguas residuales tratadas directamente, así como en recarga de acuíferos, es una opción que debe estudiarse y adoptarse cada vez más, precisamente en regiones con escasez de agua. El tratamiento y la reutilización adecuados contribuirían a una mayor seguridad alimentaria del país al generar nuevas fuentes de agua. Esta actividad creará además puestos de trabajo directos e indirectos en sectores dependientes del agua, con los beneficios que esto conlleva para la salud humana, el desarrollo y la sostenibilidad ambiental. Sin embargo, la utilización de estas estrategias exige un esfuerzo de investigación que localice y evalúe los recursos, además de establecer las mejores técnicas para su aplicación.

La recarga artificial de acuíferos es considerada en Panamá, hasta la fecha, como una técnica no convencional y es desconocida por gran parte de la población debido a la poca difusión existente de ella. Por otro lado, la población en general también tiene escaso conocimiento de qué es un acuífero y cómo funciona, $\mathrm{y}$, por tanto, mucho menos acerca de la posible opción de llevar a cabo su recarga artificial durante las estaciones de superávit hídrico para su posterior uso en las estaciones estivales o el uso de aguas residuales tratadas para ampliar las reservas de agua subterránea o usarlas para el riego. Para afrontar este reto y ante la demanda creciente de los recursos hídricos en el país, así como en la cuenca prioritaria del río La Villa, objeto de la presente investigación, las aguas residuales pueden constituir una alternativa fiable como fuente de abastecimiento para riego o potencial recarga de acuíferos, especialmente en situaciones de escasez. No obstante, para ello es preciso cambiar el paradigma de la gestión de las aguas residuales; así, estas ya no deberían verse como un problema, sino como parte de la solución para problemas a los que se está enfrentando actualmente nuestra sociedad (WWAP, 2017).

Con el propósito de contribuir al cierre de esta brecha hídrica en la cuenca del río La Villa, que representa un problema de actualidad, así como evaluar la viabilidad de implementación de soluciones tecnológicas aplicadas con éxito en otros países del mundo, como son las técnicas que comprenden la reutilización de aguas residuales postratadas para el riego y recarga de los acuíferos, se realizó el proyecto denominado "Potencialidad de uso de aguas servidas para riego y recarga de acuíferos: cuenca del río La Villa”. Este fue ejecutado con el financiamiento de la Secretaría 
Nacional de Ciencia, Tecnología e Innovación (SENACYT), por el equipo de investigación del Centro del Agua del Trópico Húmedo para América Latina y el Caribe (CATHALAC) en colaboración con los investigadores de la Universidad Pablo de Olavide (UPO) de Sevilla y la Universidad Tecnológica de Panamá (UTP), en el cual la autora fungió como investigadora principal del proyecto. El objetivo general de la presente investigación fue evaluar la sostenibilidad y viabilidad de riego y las técnicas de recarga artificial de acuíferos en la parte baja de la cuenca del río La Villa mediante el aprovechamiento de aguas residuales tratadas procedentes de la Planta de Tratamiento de Aguas Residuales (PTAR), localizada en la ciudad de Chitré, provincia de Herrera, para su posterior recuperación por procesos naturales y uso como fuente alternativa de agua. La nueva PTAR, que es la primera de su tipo en el interior del país, todavía se encuentra en la etapa de adecuación, pero ya inició de manera parcial la recolección de las aguas residuales domésticas de Chitré y La Villa de Los Santos, con una oferta a futuro de recolección y tratamiento por el orden de 7 millones de gal/día (26,500 m³ día) al año 2035 con una población beneficiaria proyectada de 79 mil habitantes.

Es importante señalar que, mediante la utilización controlada y previamente estudiada de los efluentes resultantes de la PTAR, se confía en generar beneficios agronómicos, económicos y ambientales para los habitantes de la cuenca; reduciendo de esta manera el vertimiento directo de estos efluentes a las aguas superficiales, evitando su contaminación y los problemas de eutrofización, que ya son característicos de la región. También, para el sector agrícola, esta alternativa puede representar un menor coste de producción por el contenido de nutrientes y la posible disminución en las necesidades de fertilizantes. Por otra parte, se espera a través de los distintos medios de divulgación de los resultados de la investigación y la capacitación de los actores clave en temas relacionados cambiar el concepto que la sociedad panameña en general tiene sobre las aguas residuales, las cuales actualmente se consideran un problema de salud pública en el país; sin embargo, es poca la información divulgada sobre la utilidad de esta fuente de agua una vez completada la fase de tratamiento y los beneficios sociales, económicos y ambientales que se pueden alcanzar. 


\section{Área de estudio}

El área de la presente investigación comprende la parte baja de la cuenca hidrográfica del río La Villa, que se sitúa en las provincias de Herrera y Los Santos, en la vertiente del Pacífico de la Península de Azuero, de la República de Panamá. Es una extensa zona de $160 \mathrm{~km}^{2}$ (IGNTG, 2007), con una población estimada de unas 65 mil personas, que en su gran mayoría es urbana y pertenece a los cinco corregimientos del distrito de Chitré de la provincia de Herrera y a los cinco corregimientos del distrito de Los Santos de la provincia de Los Santos (INEC, 2010). La delimitación del área de estudio fue realizada con un criterio socioeconómico; es decir, de manera independiente de la división política del área de estudio, razón por la cual algunos distritos y corregimientos sólo están contemplados de manera parcial con respecto a su división territorial administrativa (Figura 1).

Esta demarcación se efectuó tomando en consideración que en la zona evaluada la disponibilidad de agua superficial y/o subterránea para distintos usos se reduce anualmente debido a una alta concentración de población y un fuerte incremento de actividad agropecuaria. Además de la parte baja de la cuenca hidrográfica del río La Villa, el área de estudio comprende también unas pequeñas zonas de las cuencas vecinas, de los ríos Parita al noroeste y Guararé al sureste.

Figura 1. Localización regional y división administrativa del área de estudio
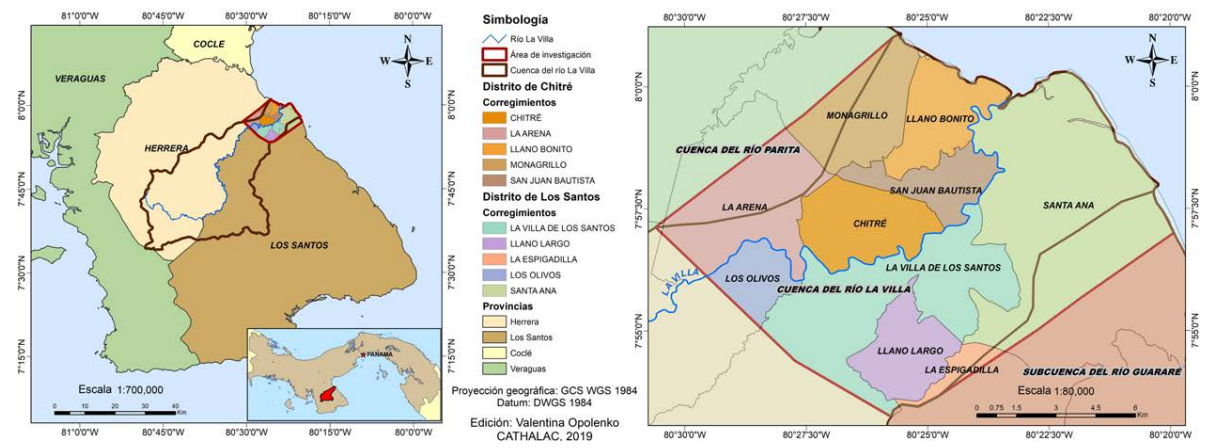

Fuente: Elaboración propia. 
Potencialidad de uso de aguas servidas para riego y recarga de acuíferos: cuenca del río La Villa, República de Panamá

El relieve del área de estudio, con una elevación media de unos 25 msnm, se caracteriza por la presencia de un amplio sector de tierras bajas (llanuras) y por tierras con aisladas colinas suaves, cuyos alineamientos muestran signos de avanzados procesos de erosión y efecto degradante de las actividades agropecuarias. A nivel general, desde la perspectiva de los rangos altitudinales, la cuenca del río La Villa se divide en partes alta, media y baja (Figura 2).

Figura 2. Rangos altitudinales y división de la cuenca del río La Villa

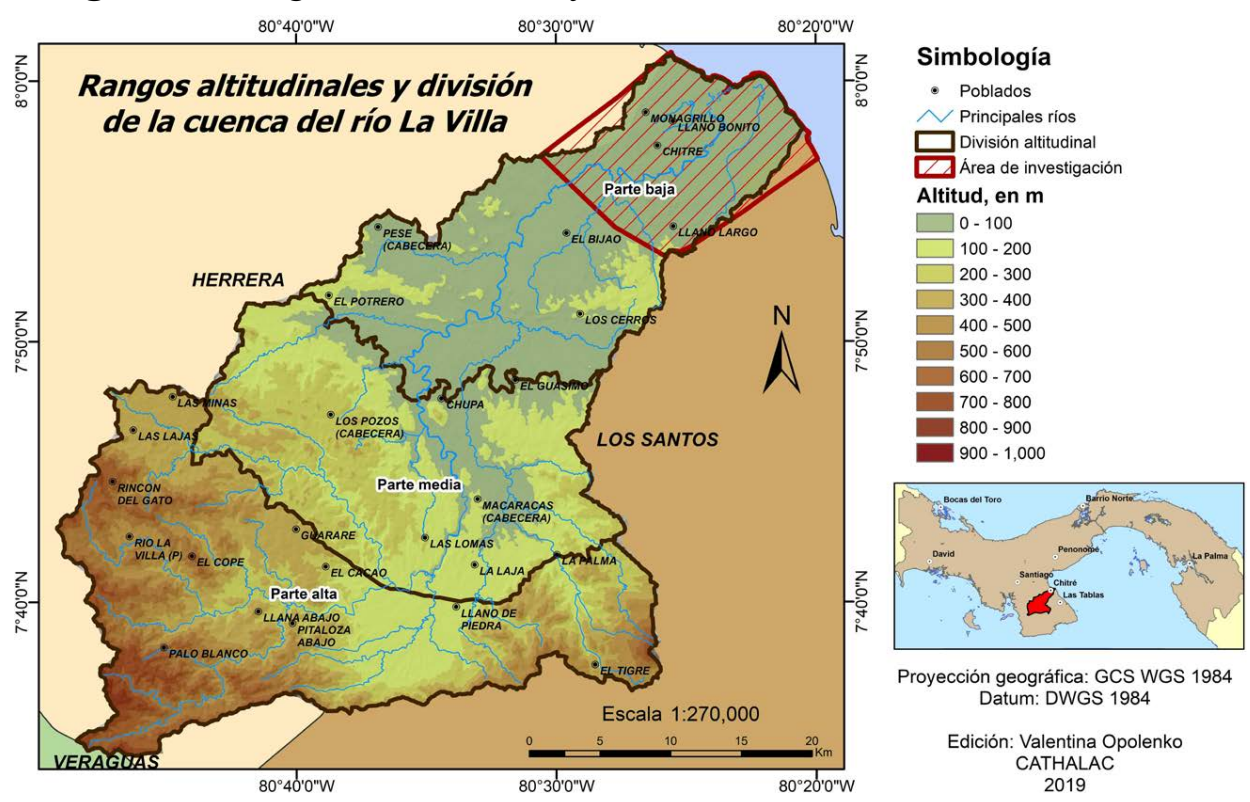

Fuente: Elaboración propia a partir de ANAM, 2008.

Los límites altitudinales quedaron establecidos de la siguiente manera (ANAM, 2008): la parte baja de la cuenca se extiende hasta una elevación de $80 \mathrm{msnm}$, la parte media se inicia en los $80 \mathrm{msnm}$ hasta los 300 msnm y la parte alta desde los $300 \mathrm{msnm}$ hasta la altura máxima de la cuenca, que sería el cerro Cacarañado con $957 \mathrm{msnm}$.

Geomorfológicamente, tomando como referencia el Mapa 4.1 de Regiones Morfoestructurales de Panamá (IGNTG, 2007), la parte baja de la cuenca del río La Villa, que también comprende la zona de estudio, está representada por la unidad denominada como Regiones Bajas 
y Planicies Litorales, que corresponde a zonas deprimidas, constituida por rocas sedimentarias marinas. La topografía varía de aplanada a poco ondulada, con declives que oscilan entre muy débil y débil. Relieve residual (colinas aisladas y diques) irregularizan el paisaje de esta unidad. Concretamente, es una zona al este de la cuenca del río La Villa que está constituida por extensas planicies y valles surcados por ríos y quebradas de curso meándrico, en donde se destacan de este a oeste los manglares y las albinas sobre una franja costera, los bajos inundables y pantanos, los terrenos cultivados y las áreas pobladas. En el contexto estructural esta unidad corresponde casi en su totalidad a litología de rocas sedimentarias del terciario sobre las cuáles se han depositado los sedimentos cuaternarios. También hay presencia de algunas pequeñas estructuras aisladas de rocas plutónicas del terciario, así como volcánicas del secundario (DGRM, 1991).

Entretanto, conforme con la taxonomía de suelos de USDA (Soil Survey Staff, 1999), los suelos que se identifican en el área de investigación pertenecen al orden de alfisoles (IDIAP, 2006). Los alfisoles tienen características de ser finos y mezclados, su color es pardo rojizo, arcillosos, son duros en seco, friables en húmedo, ligeramente adhesivos y también ligeramente plásticos. Se encuentran en zona investigada en las áreas planas y onduladas de geoformas tales como valles con sus terrazas, llanuras y pequeñas colinas, desarrollándose sobre una amplia gama de materiales parentales sedimentarios (Opolenko, 2016).

Con respecto a la cobertura y usos actuales de la tierra, predomina el uso agropecuario con $67 \%$ de la superficie total del área de estudio, de los cuales el $15 \%$ de la superficie se usa para la siembra de maíz. Sólo un $9.4 \%$ de la superficie está ocupada por bosques secundarios y $5.4 \%$ por bosques de mangle. Prácticamente las áreas de bosques están rodeadas por matorrales que parecen formar una zona de amortiguamiento o transición de cobertura boscosa a actividad agropecuaria (Figura 3).

\section{Caracterización geológica}

El marco geológico de la cuenca del río La Villa, así como de la zona de investigación, se desarrolla en un ambiente complejo por su evolución histórica de pequeño arco de islas y mares poco profundos a un istmo afectado por intensa actividad volcánica acompañada 
Potencialidad de uso de aguas servidas para riego y recarga de acuíferos: cuenca del río La Villa, República de Panamá

Figura 3. Cobertura y principal uso de la tierra en la zona de investigación
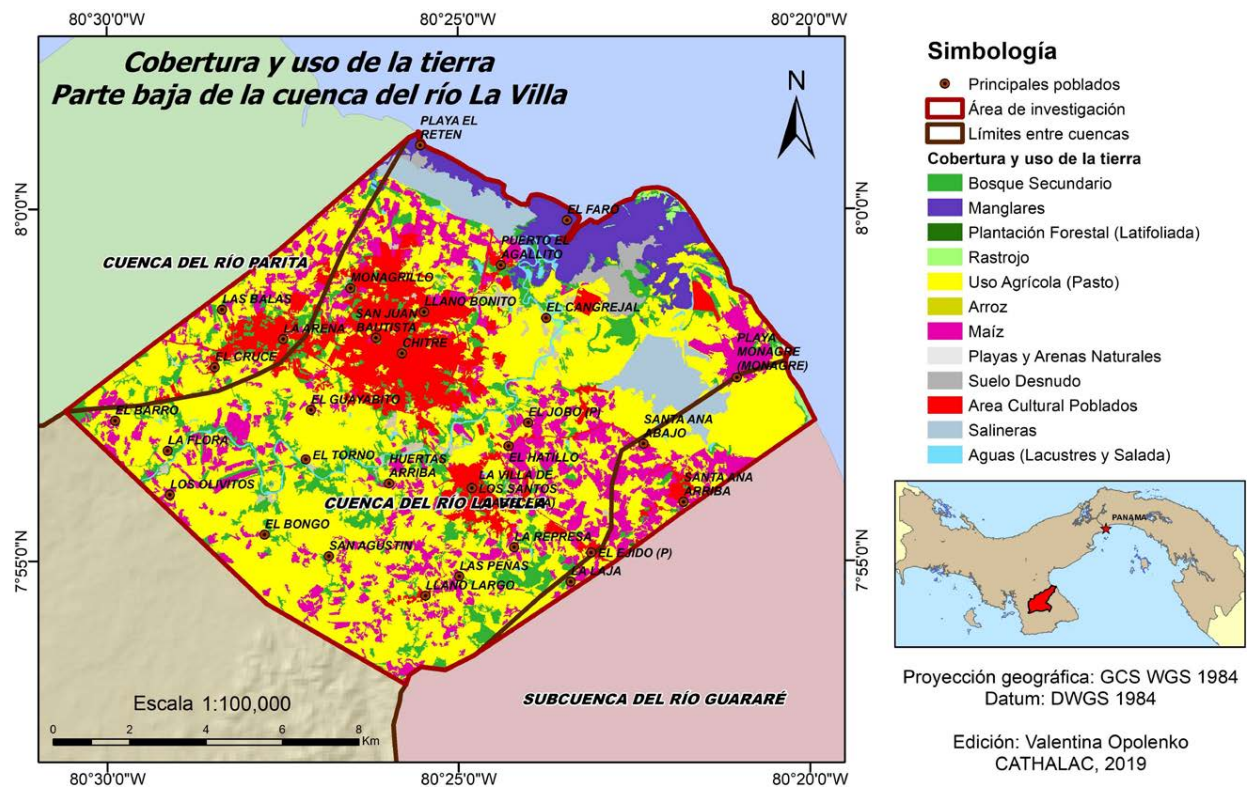

Fuente: Elaboración propia.

de emersiones, regresiones y movimientos tectónicos con vectores multidireccionales, erosión y sedimentación en el plano horizontal. El conjunto litológico que constituye el área de estudio presenta rocas asociadas a la actividad volcánica de la península de Azuero, un elemento fundamental para entender cómo se formó el relieve, debido a que muchos de los cambios que se dieron en esta parte de la cuenca dependen de la naturaleza de las rocas, ya que el comportamiento de estos relieves se producirá de una manera concreta ante los empujes tectónicos, los agentes de erosión y transporte, así como la variación del clima (Opolenko, 2016).

Según el Mapa Geológico de Panamá (DGRM, 1991), el conjunto de formaciones geológicas que constituyen el área investigada es representado por las rocas de origen ígneo y sedimentario. Entre las rocas ígneas se distinguen dos tipos: plutónicas y volcánicas. La evolución de la geología histórica de la zona investigada muestra un cuadro de intercalamientos de formaciones sedimentarias, ígneas efusivas e intrusivas, que posteriormente fueron afectadas por levantamientos y 
movimientos tectónicos que han moldeado con importantes fallas regionales su configuración actual (Figura 4).

Figura 4. Mapa geológico del área de investigación

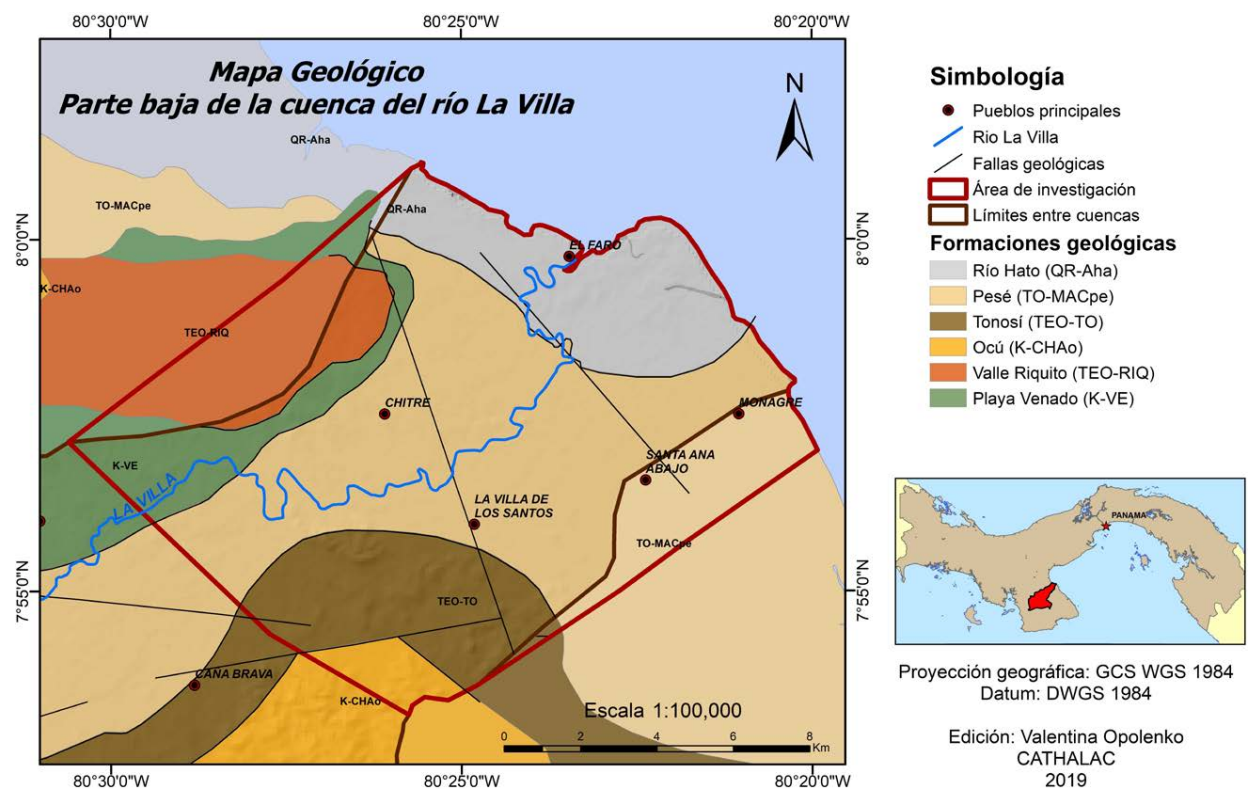

Fuente: Elaboración propia a partir de DGRM, 1991.

En lo que respecta a tectónica, en el plano horizontal las tectolineales tienen la dirección este-oeste, pero también están interceptadas por fallas con dirección noroeste-sureste. Además de fracturamientos regionales, existen otros de menor dimensión, relacionados con el sistema de diaclasas o juntas más pequeñas, lo que refleja la topografía y composición de la red hidrográfica dentro de la cuenca, incluida la zona de investigación (Tabla 1).

\section{Marco teórico-conceptual}

El agua, como recurso vital ligado a un manejo sostenible y confiable que beneficie a los sectores económicos y sociales de un país o región, es un tema que se ha convertido crecientemente en algo complejo y problemático, particularmente si la demanda global sobrepasa la disponibilidad o si el agua demerita su calidad en su uso. El incremento de las demandas, 
Valentina Opolenko

Potencialidad de uso de aguas servidas para riego y recarga de acuiferos: cuenca del río La Villa, República de Panamá

Tabla 1. Formaciones geológicas y la litología del área de estudio

\begin{tabular}{|c|c|c|c|}
\hline Periodo & Formación & Símbolo & Descripción \\
\hline \multirow{4}{*}{ Cuaternario } & Río Hato & QR-Aha & $\begin{array}{c}\text { Conglomerado, arenisca, lutita, tobas, } \\
\text { areniscas no consolidadas y pómez }\end{array}$ \\
\hline \multirow{2}{*}{ Terciario } & Pesé & TO-MACpe & Tobas continentales, areniscas, calizas \\
\cline { 2 - 4 } & Tonosí & TEO-TO & Lutitas, areniscas \\
\hline Secundario & Ocú & K-CHAo & Calizas y tobas \\
\hline \multicolumn{4}{|c|}{ Formaciones Volcánicas (Extrusivas) } \\
\hline Secundario & Playa Venado & K-VE & Basaltos, pillow lavas \\
\hline \multicolumn{4}{|c|}{ Formaciones Plutónicas (Intrusivas) } \\
\hline Terciario & Valle Riquito & TEO-RIQ & Cuarzodionitas, noritas y gabros \\
\hline
\end{tabular}

Fuente: Elaboración propia a partir de DGRM, 1991.

agravado por períodos de sequía (meteorológica e hidrológica), lleva a la necesidad de utilizar otros tipos de recursos donde resulten necesarios, siendo el agua regenerada uno de ellos. El desarrollo de tecnologías avanzadas en las últimas décadas dedicadas a la depuración de aguas residuales permite el uso de este recurso hídrico, generando una fuente de agua alternativa para actividades que no requieran calidad de agua potable o liberando agua de fuentes naturales para destinarla al abastecimiento (De Bustamante et al., 2016).

La reutilización de las aguas residuales depuradas para usos como el riego o la recarga artificial de acuíferos permite, además de la recuperación parcial de los costes asumidos en el proceso de depuración, proporcionar un recurso de agua alternativo en zonas con déficit hídrico, siempre y cuando ofrezca garantía de suministro y seguridad tanto desde el punto de vista sanitario como ambiental (Casas, Tapias, de Bustamante, de Miguel \& Lillo, 2011). Dependiendo de la situación local, también podría haber beneficios para los agricultores si logran evitar algunos de los costos de extraer aguas subterráneas, al mismo tiempo que los nutrientes presentes en las aguas residuales ayudan a ahorrar en fertilizantes. Igualmente, cuando las características climáticas y geográficas lo permitan, el tratamiento de bajo costo de las aguas residuales puede ser una opción viable a través del uso de humedales artificiales, los cuales tienen tres funciones básicas que les confieren atractivo potencial para el tratamiento de aguas residuales: fijan físicamente los contaminantes en la superficie del suelo y la materia orgánica, utilizan y transforman los elementos por medio de los 
microorganismos y logran niveles de tratamiento consistentes con un bajo consumo de energía y poco mantenimiento (Delgadillo, Camacho, Pérez \& Andrade, 2010).

Por lo tanto, el uso de agua regenerada en agricultura es una opción perspectiva que se está estudiando y adoptando cada vez más en regiones con escasez de agua, poblaciones urbanas crecientes y con una mayor demanda de agua de riego (FAO, 2013). El riego, tanto urbano, recreativo como agrícola, presenta el principal potencial de utilización del agua regenerada, ya que los mayores consumos de agua se producen en este sector. La reutilización de las aguas depuradas depende de diversos factores que deben estudiarse cuidadosamente tales como el método de riego desde el punto de vista del efecto sobre los trabajadores y los consumidores, niveles de riesgo asociados con los diferentes tipos de cultivos que se riegan con agua regenerada, entre otros.

Además de ser un recurso de gran valor para la agricultura, el agua regenerada también es una fuente no convencional de recursos útiles para la recarga de acuíferos. La recarga artificial de acuíferos se ha usado desde la antigüedad para gestionar los recursos hídricos disponibles y puede definirse, según Custodio \& Llamas (1976) como el conjunto de técnicas que permiten aumentar la disponibilidad de aguas subterráneas con la calidad necesaria mediante una intervención consciente, directa o indirecta, en el ciclo natural del agua. La recarga de un acuífero se encuentra condicionada por diversos factores de carácter geológico, climático, de ocupación del terreno, morfológico, topográfico, de calidad del agua disponible o conseguible, temporales en cuanto al momento que se dispone de agua, de coste del agua, administrativos, legales y socio-ecológicos, entre otros. Existe un amplio espectro de métodos que se aplican para la recarga que varían desde los más simples, como la recolección y recarga del agua de lluvia a pequeña escala, hasta los más complejos, como la inyección profunda con recuperación en acuíferos. Estos forman parte de dos grandes grupos en función del tipo de recarga que se efectúe, ya sea por infiltración a través de la superficie del terreno, o bien, por inyección directa del agua hasta el acuífero mediante una perforación que lo atraviesa.

Los métodos superficiales se emplean en acuíferos libres, en los que no se tienen capas de baja permeabilidad próximas a la superficie del terreno, para que el agua pueda llegar más rápidamente al acuífero, sin barreras 
naturales que se lo impidan. Se basan en la extensión del agua, de manera que se consiga la mayor superficie de contacto agua-terreno, por medio de los siguientes dispositivos: represas, gaviones, drenes, zanjas y sistemas de surco, balsas, canales, campos de extensión. Los métodos de recarga en profundidad se utilizan en acuíferos confinados, semiconfinados o multicapas, en los que se presentan formaciones de baja permeabilidad cubriendo al acuífero que se pretende recargar. El agua se introduce en el acuífero mediante pozos, drenes y galerías horizontales. Para escoger el método de recarga adecuado, deben considerarse los siguientes aspectos: el propósito de uso del recurso, la instalación más adecuada, tanto desde el punto de vista técnico como económico, la disponibilidad, origen y calidad del agua de recarga, así como la tipología del acuífero. Las tareas de prospección de un reservorio subterráneo o acuífero están ligadas a principios científicotecnológicos que involucran ampliar el conocimiento en zonas perspectivas, revelándose con mayor detalle las características estructurales de las formaciones rocosas del subsuelo, como el criterio de investigar de lo general a lo particular bajo el principio de las aproximaciones sucesivas (Klimentov \& Kononov, 1982).

Para la caracterización del acuífero receptor y del área afectada por la posible operación de recarga se deben realizar los estudios para determinar la capacidad de transmisión y almacenamiento del acuífero; determinar la geometría y profundidad del acuífero, de la lámina de agua, los eventuales horizontes de baja permeabilidad suprayacentes al acuífero; cuantificar el volumen disponible para el almacenamiento; identificar y determinar los usos del suelo y del agua. Las características del acuífero receptor de la recarga, especialmente los factores como el espesor, la permeabilidad y almacenamiento, condicionan la viabilidad de las operaciones de recarga artificial y son claves para establecer la elección del método de recarga, ya que cuanto mejor caracterizado esté el acuífero, más adecuado será el diagnóstico sobre la viabilidad e idoneidad de su recarga (IGME, 2010).

\section{Marco metodológico}

El desarrollo metodológico de la presente investigación comprendió el análisis de los procedimientos que permiten la evaluación de la posibilidad de implementación en Panamá de soluciones tecnológicas para el reúso de aguas residuales, utilizadas con éxito en otros países con 
mayor o menor grado de desarrollo que el nuestro. Tales métodos son la reutilización directa con fines de riego de aguas depuradas en humedales artificiales y recarga superficial de acuíferos de manera indirecta (infiltración de excedentes) durante el riego con aguas residuales postratadas. La aplicación de estos procedimientos permite proporcionar un recurso de agua alternativo en zonas con déficit hídrico como lo es la Península de Azuero y, especialmente, la parte baja de la cuenca del río La Villa, ya que el uso de agua regenerada en agricultura es una opción que se está estudiando y adoptando cada vez más en regiones con escasez de agua, poblaciones urbanas crecientes y con una mayor demanda de agua de riego (FAO, 2013).

Con base en los resultados esperados, la metodología que se aplicó en la ejecución del proyecto "Potencialidad de uso de aguas servidas para riego y recarga de acuíferos: cuenca del río La Villa", debido a la complejidad de los factores presentes, tuvo sus fundamentos en un análisis multidisciplinario a través de un diagnóstico biofísico y socioeconómico, ya que este enfoque socio-ecosistémico en el cual se tiene en consideración a los seres humanos, a la naturaleza y vínculos entre ellos, facilitó entender el contexto en el cual se realizó el presente trabajo. También, tomar en cuenta los ecosistemas de los cuales dependía el éxito de la investigación ha sido un paso muy importante debido a que el concepto ecosistémico o socioecológico es holístico y se refiere a la combinación de diferentes aspectos ecológicos, biológicos, científicos, económicos, políticos, culturales, sociales, entre otros; centrándose no sólo en los componentes de un sistema, sino también en sus relaciones, interacciones y retroalimentaciones (Farhad, 2012).

Además, el enfoque de conservación de biodiversidad y la rehabilitación ecológica de la cuenca se considera como un proceso importante para superar el estado actual de degradación de los recursos naturales $\mathrm{y}$, por ende, mejorar a futuro las condiciones de producción y productividad en la zona evaluada. Los mecanismos de levantamiento de información se basaron en la revisión bibliográfica, análisis de mapas temáticos de la zona, visitas de campo, toma de imágenes aéreas con el uso de drones y entrevistas a la comunidad. El diagnóstico socioeconómico ejecutado tuvo como objetivo caracterizar la condición actual de la parte baja de la cuenca del río La Villa en términos de su densidad 
de población y su distribución al interior de la unidad hidrográfica, sus niveles de marginación y de desarrollo humano, sus dinámicas migratorias, sus actividades económicas más importantes, la cobertura de los servicios de saneamiento y todos aquellos datos susceptibles de ser representados espacialmente, que den a la cuenca un sentido de unidad regional y permitan, en un momento dado, planificar las acciones de manejo y conservación de los recursos tomando a la cuenca como unidad de planeación. De esta manera, el desarrollo metodológico con el enfoque multidisciplinario permitió durante la ejecución del proyecto establecer el uso de agua regenerada en agricultura como una opción potencial a considerar. Otro aspecto abordado, además de uso de agua regenerada para riego, ha sido la viabilidad de la recarga artificial de acuíferos con este tipo de agua.

\section{Tecnología no convencional para la adecuación de aguas postratadas}

Los humedales artificiales son una tecnología para el tratamiento de aguas residuales que puede ser considerada como un complejo ecosistema, en el que los principales componentes son el sustrato que sirve de soporte a la vegetación y permite la fijación de la población microbiana, que participa en la mayoría de los procesos de eliminación de los contaminantes presentes en las aguas a tratar; la vegetación contribuye a la oxigenación del sustrato y a la eliminación de componentes no deseables y, por último, el agua a tratar, que circula a través del sustrato y de la vegetación. De esta manera, la depuración de las aguas residuales se consigue haciéndolas pasar a través de humedales artificiales, en los que tienen lugar procesos físicos, biológicos y químicos de forma simultánea, que conducen a obtener unos efluentes finales depurados (Salas, Pidre, \& Sánchez, 2007).

Existen diferentes tipos o esquemas de humedales artificiales que pretenden replicar los procesos naturales. Basados en las condiciones existentes en el área de estudio y los objetivos trazados, para esta investigación, en la fase experimental, se escogió como herramienta tecnológica el concepto de un humedal artificial de flujo subsuperficial (HAFSS), cuyas estructuras de ensayo fueron instaladas en la PTAR, donde el agua a tratar circula de modo horizontal a través de un material granular por debajo del nivel del sustrato, de permeabilidad suficiente, confinado en un recinto impermeabilizado. Este material granular sirve de soporte para el 
enraizamiento de la vegetación emergente, cuya alimentación se realiza de forma continua (Figura 5).

Con el fin de verificar el funcionamiento hidráulico y comprobar si los módulos sembrados con las especies de plantas seleccionadas estaban efectuando post-depuración al agua de descarga de la PTAR, se realizaron evaluaciones de calidad del agua de la entrada y la salida de los módulos. La concentración de cada parámetro evaluado fue comparada con el límite máximo permitido del Reglamento Técnico DGNTI-COPANIT 35-2019.

\section{Recarga de acuíferos}

Para poder seleccionar el método de recarga de acuíferos con aguas postratadas que sería propuesto como método base de la investigación fue indispensable realizar la caracterización geológica e hidrogeológica del área delimitada del estudio con el fin de disponer de un conocimiento adecuado del acuífero a recargar, teniendo en cuenta las condiciones geológicas locales, como la interrelación del sistema de fallamientos asociados a los eventos tectónicos con el conjunto de formaciones geológicas representadas por rocas de origen ígneo y sedimentario, que constituyen el área investigada propiamente dicha, y que determinarán la operación de la obra de recarga y el flujo de las aguas subterráneas en el acuífero. Para seleccionar el método potencial de recarga y analizar su viabilidad fue necesario identificar los acuíferos idóneos con capacidad de almacenamiento de

Figura 5. Esquema de un humedal artificial de flujo subsuperficial (HAFSS)

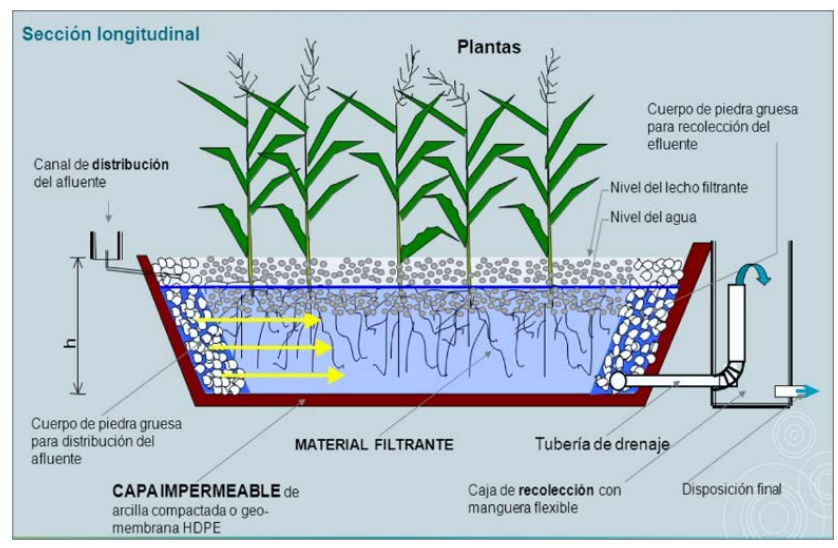

Fuente: Adaptado de Lara y Vera, 2005. agua infiltrada, realizando para este fin las exploraciones geológicas, geofísicas e hidrogeológicas del área estudiada. La metodología implementada durante la realización de la investigación geofísica ha sido el cateo de las capas litológicas presentes en el área con la aplicación de técnicas geofísicas en 
su modalidad de Sondeos Eléctricos Verticales (SEV), revelándose, con el uso de los programas especializados de interpretación WinSEV y Roc$k W o r k s$ a través de un bloque modelo litológico generado, la estructura del reservorio subterráneo. La exploración geofísica también fue combinada con la prospección geológica de superficie y los ensayos de permeabilidad, que dieron referencia de la capacidad de los suelos de aceptar aguas de lluvia o excedentes de riego durante la estación seca.

Con el propósito de obtener la información sobre los parámetros hidráulicos, como la tasa de infiltración, volumen de esta, conductividad hidráulica, entre otros; se implementaron dos métodos de ensayos de campo, como lo son el de Doble Anillo de Muntz para la parte superior de la cubierta de suelo, y para el flujo más profundo, ensayos tipo Porchet, que permiten estimar la tasa de infiltración que ayudaría a reponer las aguas subterráneas. Por lo tanto, combinando la técnica de exploración geoeléctrica con ensayos de permeabilidad fue posible definir los volúmenes de agua que estarían involucrados en la recarga, ya que, conociéndose los espesores de las distintas capas litológicas también puede inferirse su porosidad efectiva, por ende, los volúmenes de agua que las mismas pueden almacenar.

Además, la calidad del agua con la que se plantea realizar la recarga de acuíferos o riego también es un factor condicionante de la viabilidad de este tipo de proyecto. Por lo tanto, se requiere una adecuada evaluación de las características físicas, químicas y biológicas del agua regenerada. Básicamente, una operación de Recarga Artificial de Acuíferos (RAA) es viable, desde el punto de vista técnico, cuando confluyan tres factores: que exista una demanda que atender, entendida ésta como la finalidad principal de la operación de recarga; que existan caudales excedentes de agua en determinadas épocas del año (disponibilidad hídrica); y que el acuífero al mismo tiempo disponga de una capacidad de almacenamiento de dichos caudales. Estos tres factores antes mencionados han sido identificados, evaluados y seleccionados en las etapas de la presente investigación, considerando todos los estudios técnicos realizados, así como las disposiciones legales vigentes en materia de reutilización de aguas residuales tratadas. 


\section{Resultados y discusión}

\section{Adecuación del agua de descarga de la PTAR: Fase experimental}

Con el fin de establecer el grado de mejoras deseables (afino) y el tipo de manejo posterior que se daría para conseguir los resultados óptimos

Figura 6. Sitio de ubicación de los módulos experimentales en el predio de la PTAR

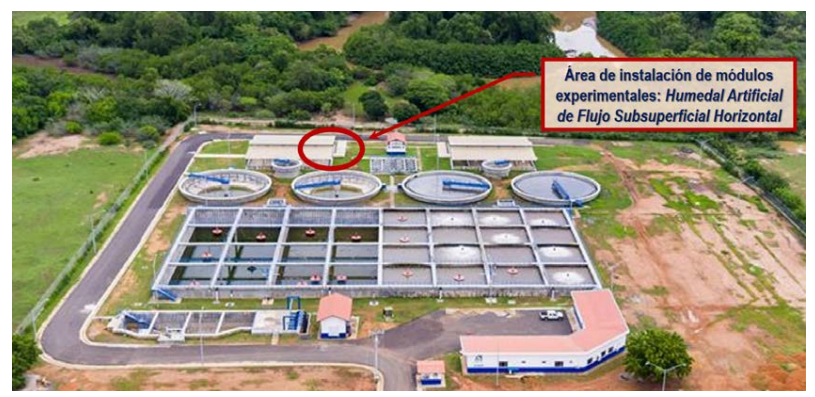

Fuente: Elaboración propia.

Figura 7. Especificaciones técnicas para el diseño de los módulos experimentales

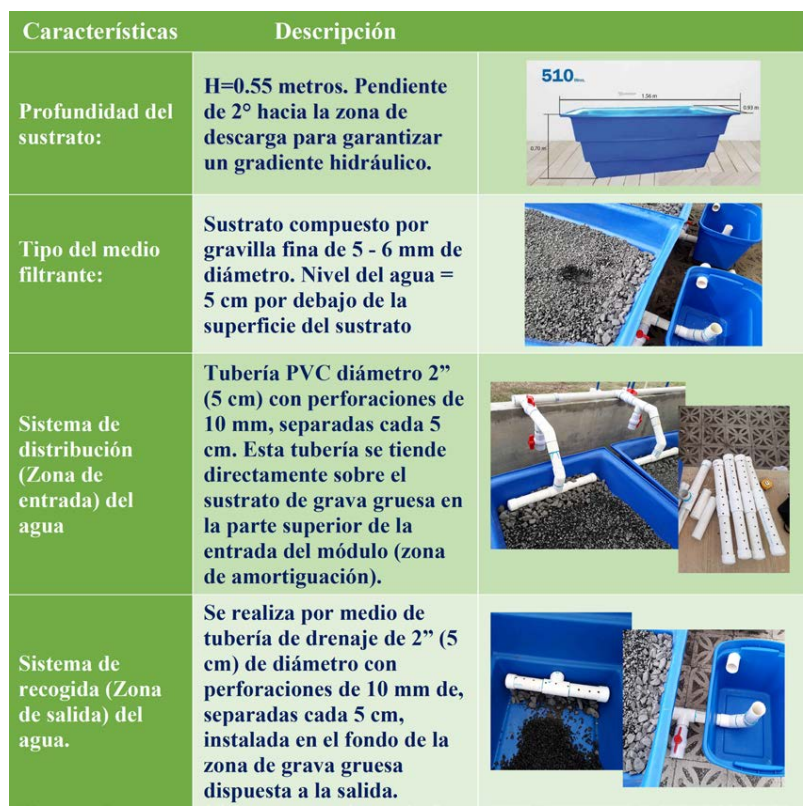

Fuente: Elaboración propia. en el uso de aguas residuales postratadas, lo anterior establecido en los objetivos del proyecto, en los predios de la PTAR (previo acuerdo y autorización de la administración) fueron construidos seis módulos experimentales de humedales artificiales de flujo subsuperficial horizontal a escala piloto, considerando los siguientes parámetros de diseño (Figuras 6 y 7).

Para poder alimentar estos módulos con el agua de descarga de la PTAR de manera interrumpida, se instaló un tanque elevado de 750 litros. Se calculó el tiempo de retención o tránsito de agua por los módulos, que en este caso concreto fue de 24 horas (Figura 8). 
Potencialidad de uso de aguas servidas para riego y recarga de acuíferos: cuenca del río La Villa, República de Panamá

Como puede Figura 8. Esquema del sistema experimental observarse, el sisteinstalado en la PTAR, con el crecimiento de ma de ensayo estuvo colocado bajo techo, protegido de la lluvia y la radiación solar directa; salvo el tanque para la reserva del agua que alimenta a los sistemas (agua de entrada). El agua que alimentó a los módulos ha sido tomada de modo directo del tanpasto 5 días después de su siembra en los módulos
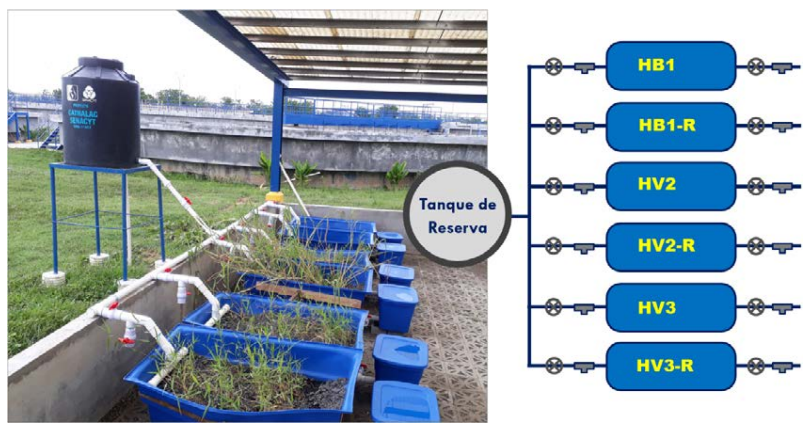

Fuente: Elaboración propia. que de sedimentación o clarificación más cercano, con el fin de evitar su cloración final, lo que pudiera afectar el buen funcionamiento de los humedales experimentales. Los primeros dos módulos denominados $\mathrm{Hu}$ medal Blanco 1 (HB1) y Humedal Blanco 1 Réplica (HB1-R) incluyeron únicamente el sustrato de gravilla fina de 5-6 mm de diámetro, de 0.55 $\mathrm{m}$ de profundidad. En otros dos módulos Humedal 2 (HV2) y Humedal 2 Réplica (HV2-R), aparte de contener el sustrato, se les plantó las gramíneas Pasto Alemán. El mismo procedimiento se aplicó en otros dos humedales Humedal 3 (HV3) y Humedal 3 Réplica (HV3-R), en los cuales fue sembrado el pasto Tanner (Figura 9).

Figura 9. Módulos experimentales de humedales de flujo subsuperficial horizontal

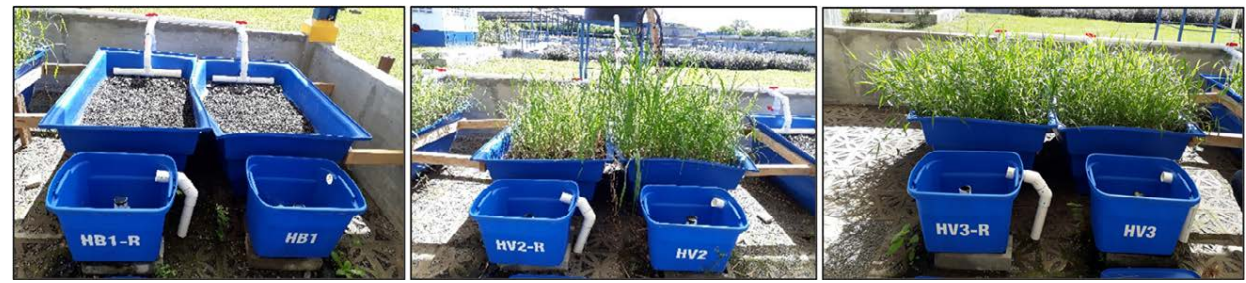

Fuente: Elaboración propia. 
Las dos variedades de vegetación sembradas en módulos experimentales, tales como el pasto Alemán y pasto Tanner, fueron seleccionadas de entre las 20 especies de pastos y forrajes importantes de Panamá por su fisiología, productividad, valor nutritivo y la mejor adaptación en el área de estudio (MIDA, 2009).

Tomando en consideración que en la parte baja de la cuenca del río La Villa se concentra la gran mayoría de actividades ganaderas, con la selección de estas especies de pasto no sólo se trató de evaluar la eficiencia de remoción de las plantas de los contaminantes, sino también de buscarles una utilidad inmediata como fuente de forraje para el sector ganadero. Además, esto ayudaría a minimizar de igual forma el impacto sobre el recurso hídrico que se genera diariamente, en especial para la época de verano.

En términos generales, el pasto Alemán (Echinochloa polystachya) es una planta herbácea perenne que pertenece a la familia de gramíneas (Poaceae). Los tallos pueden crecer $2 \mathrm{~m}$ de altura y las hojas pueden ser de 2 a $5 \mathrm{~cm}$ de ancho y de 10 a $30 \mathrm{~cm}$ de largo. Es un pasto de excelente calidad, ideal para heno, ya que crece rápido y vigoroso. El período de establecimiento varía entre 4 y 6 meses. El pastoreo puede hacerse cada 45 días. Produce de 20-25 toneladas de forraje verde en corte/ha, lo cual equivale a una capacidad de carga promedio hasta 5 animales/ha/año. Los contenidos de proteína cruda en praderas bien manejadas están entre $10-13 \%$, y la digestibilidad entre 50-63\%.

Mientras tanto, el pasto Tanner (Brachiaria arrecta), que también pertenece a la familia de las gramíneas, es tolerante a la sequía, de crecimiento agresivo y de hojas oblongas que miden $15 \mathrm{~cm}$ de largo y $14 \mathrm{~mm}$ de ancho. Produce entre 25 y 30 toneladas de MS/ha/año, con un contenido de proteína cruda de $8-12 \%$ y una digestibilidad de $55-60 \%$. Puede llegar a soportar 3 unidades animales por hectárea (Peters, Franco, Schmidt \& Hincapié, 2011).

Se considera como una referencia para contenido nutricional óptimo el Indicador de Proteína (\%) para Gramíneas de $11.4 \%$ y la siguiente clasificación de Digestibilidad (\%): Alto (>70); Medio (55-70); Bajo (45-55) y Muy Bajo $(<45)$.

Concretamente, durante la ejecución de la fase experimental de la presente investigación, se realizaron a los 45 y 90 días después de la siembra los cortes de pasto en los módulos. Los datos de crecimiento del pasto se obtuvieron mediante la medición de la base de la planta hasta la parte 
más alta, con 5 tomas por cada módulo experimental, el cual se promediaba. A las plantas se les realizó el análisis bromatológico y con los datos de medición se determinaron las curvas de su crecimiento.

Se puede observar en las gráficas (Figura 10) sobre el crecimiento del pasto Alemán, al igual que el del pasto Tanner, cómo a mediados de la semana 4 su curva de crecimiento tiende a cambiar, y este comportamiento se debe a que en las semanas 5 y 6 la planta entra en su etapa fisiológica donde crea su inflorescencia.

Figura 10. Curvas de crecimiento de pastos (a) Alemán y (b) Tanner
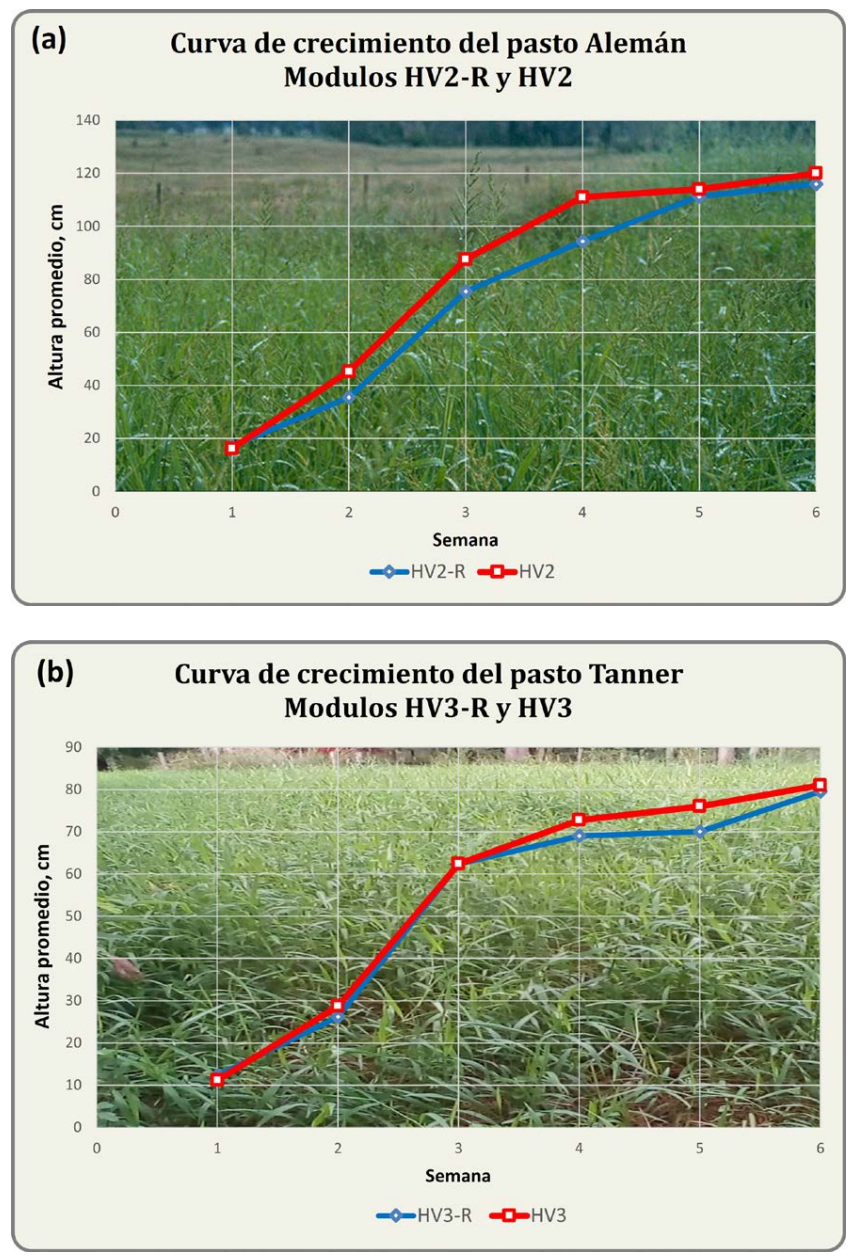

Fuente: Elaboración propia. 
Si se analizan los rendimientos en pesos en los módulos (extrapolados a toneladas por hectárea), se observa que el pasto Alemán en el módulo HV2 tuvo la mayor producción con $34.5 \mathrm{tn} / \mathrm{ha}$, seguido por el pasto Tanner (HV3-R) con un rendimiento de $17.5 \mathrm{tn} /$ ha (Figura 11). Los valores de pasto Alemán han sido muy prometedores, ya que la producción nacional de maíz en materia fresca, cuando llega a más de 25 tn/ha, se considera como buena.

Figura 11. Rendimiento de las plantas en módulos experimentales, en toneladas/hectárea

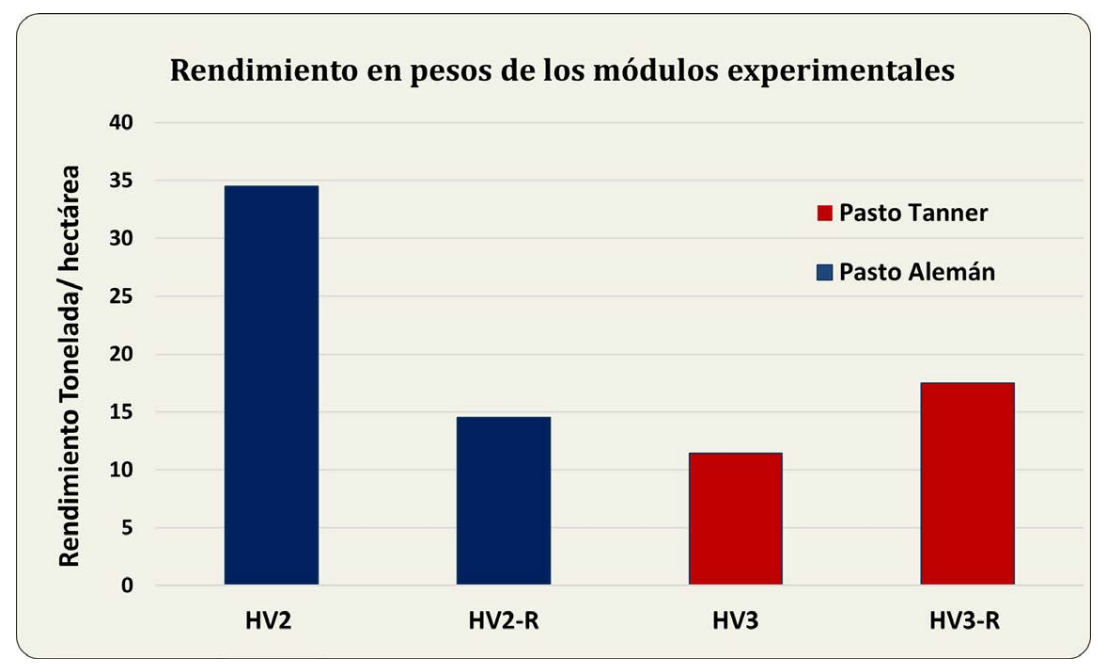

Fuente: Elaboración propia.

En los resultados de análisis bromatológico de la vegetación de cada módulo se puede observar que ambas especies tienen buen contenido de proteína, $11 \%$ para el pasto Alemán y $16 \%$ para el pasto Tanner. Mientras tanto, los valores de digestibilidad están en un rango clasificado como "medio-alto" (pasto Alemán con 67\% y pasto Tanner con 68.5\%). Los resultados obtenidos señalan a ambos pastos muy prospectivos como fuente de forraje para la alimentación de los bovinos. Por ejemplo, con el riego del pasto Alemán durante la estación seca (verano) con el agua postratada de la PTAR y luego afinada en los humedales artificiales establecidos en las estructuras de las antiguas lagunas de oxidación, se puede proporcionar alimentación a unos 31 mil bovinos en el área del proyecto en la parte baja de la cuenca del río La Villa. 
Potencialidad de uso de aguas servidas para riego y recarga de acuíferos: cuenca del río La Villa, República de Panamá

\section{Calidad del agua de descarga de los módulos y del efluente de la PTAR}

Una vez establecidos los módulos de ensayo, sembrado el pasto y puesto en marcha el sistema, el agua de salida de cada módulo se evaluó por un periodo de aproximadamente cinco meses. Inicialmente, las pruebas analíticas se realizaron cada 15 días, mientras que el último mes las pruebas se realizaron semanalmente. De esta forma, durante las campañas de medición de calidad del agua de descarga de los módulos, se corroboró en el campo a través de los análisis de agua postratada la capacidad del sistema experimental de humedales artificiales de flujo subsuperficial horizontal de remover los microorganismos, degradar el material orgánico, eliminar sólidos en suspensión, excesos de nitrógeno y fósforo, entre otros; del agua procedente de la PTAR, la cual ha sido denominada como "Entrada" (Figura 12).

Durante este periodo de pruebas, en los módulos experimentales se monitorearon los parámetros del agua de descarga $\mathrm{y}$, como se puede apreciar en la Tabla 2 , los resultados promedio obtenidos para los parámetros fisicoquímicos y de metales evaluados durante las campañas de muestreo para un tiempo de retención o tránsito de agua establecido de un día muestran en la gran mayoría de

Figura 12. Graficas de remoción de (a) fosforo y (b) nitrógeno en módulos experimentales
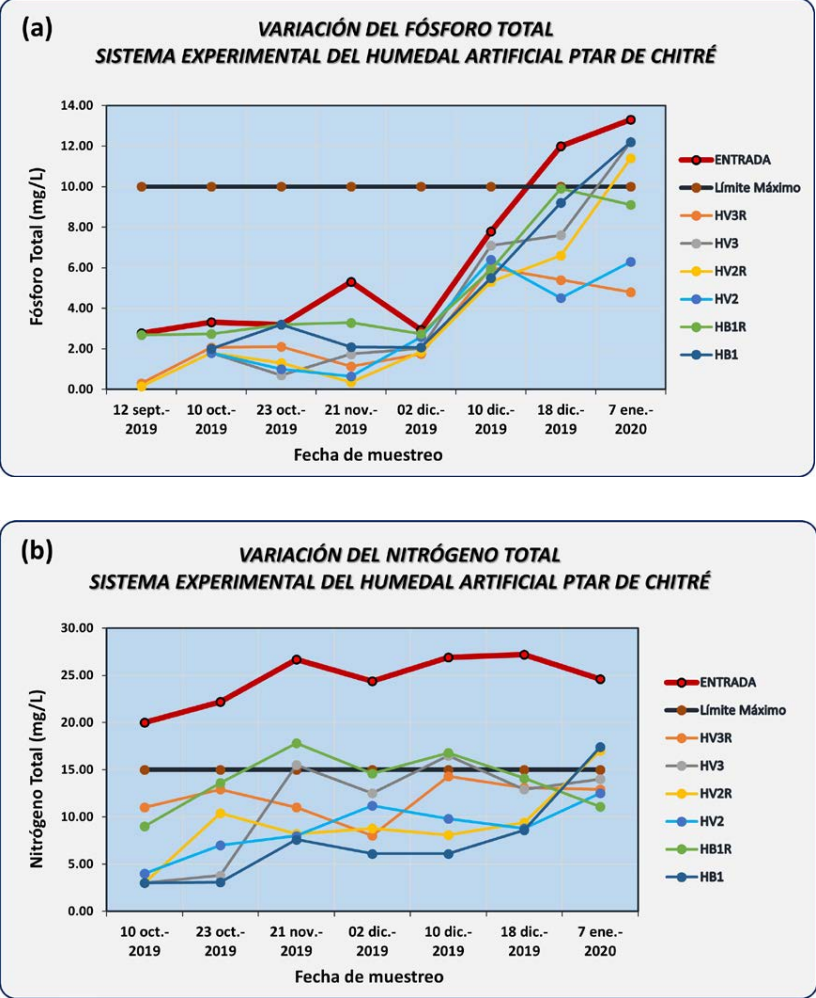

Fuente: Elaboración propia. 
sus parámetros la capacidad del sistema de humedales artificiales de flujo subsuperficial horizontal de realizar con éxito la tarea de afino del agua postratada, para su posterior uso en riego agrícola o recarga de acuíferos por infiltración de los excedentes de este riego.

Tabla 2. Valor promedio de parámetros analizados en los módulos de prueba

\begin{tabular}{|l|r|r|r|r|r|r|r|}
\hline \multicolumn{1}{|c|}{ PARÁMETRO } & ENTRADA & HV3R & \multicolumn{1}{c|}{ HV3 } & HV2R & \multicolumn{1}{c|}{ HV2 } & HB1R & HB1 \\
\hline $\mathrm{pH}$ & 7.32 & 6.96 & 7.00 & 6.96 & 6.92 & 7.40 & 7.38 \\
\hline OD (\%) & 55.51 & 141.69 & 31.76 & 26.72 & 31.21 & 24.37 & 32.34 \\
\hline OD $(\mathrm{mg} / \mathrm{L})$ & 4.19 & 6.78 & 2.46 & 42.08 & 2.44 & 1.88 & 2.51 \\
\hline Conductividad (MicroS/cm) & 824.00 & 705.85 & 762.56 & 788.40 & 744.67 & 726.30 & 757.44 \\
\hline TDS (mg/L) & 412.56 & 408.50 & 381.56 & 394.30 & 372.44 & 363.30 & 376.11 \\
\hline Temperatura & 29.71 & 28.19 & 28.07 & 27.63 & 27.66 & 27.69 & 27.69 \\
\hline Fosfato (mg/L) & 8.86 & 4.57 & 6.19 & 4.58 & 4.36 & 8.17 & 7.43 \\
\hline Fósforo de fosfato (mg/L) & 2.94 & 1.48 & 2.02 & 1.47 & 1.42 & 2.66 & 2.36 \\
\hline Fósforo Total (mg/L) & 11.03 & 5.40 & 8.97 & 7.77 & 5.73 & 8.30 & 8.97 \\
\hline Nitrógeno Total & 24.57 & 10.48 & 11.17 & 8.19 & 8.76 & 12.26 & 7.41 \\
\hline Hierro (mg/L) & 0.159 & 0.046 & 0.021 & 0.035 & 0.047 & 0.011 & 0.019 \\
\hline Cromo (mg/L) & 0.004 & 0.007 & 0.020 & 0.010 & 0.024 & 0.018 & 0.020 \\
\hline Cobre (mg/L) & 0.020 & 0.014 & 0.014 & 0.014 & 0.024 & 0.009 & 0.006 \\
\hline DQO (mg/L) & 71.86 & 58.14 & 34.14 & 44.00 & 42.43 & 37.83 & 49.33 \\
\hline Turbiedad (UNT) & 88.47 & 39.73 & 24.73 & 57.43 & 45.60 & 41.13 & 35.10 \\
\hline Cloruros (mg/L) & 106.67 & 113.33 & 113.33 & 113.33 & 113.33 & 113.33 & 120.00 \\
\hline Cloruro de sodio (mg/L) & 170.67 & 181.33 & 181.33 & 181.33 & 181.33 & 181.33 & 192.00 \\
\hline Dureza (g/gal de CaC03) & 10.33 & 10.67 & 10.67 & 11.67 & 9.33 & 9.33 & 9.33 \\
\hline Dureza (mg/L de CaC03) & 2729.78 & 2817.84 & 2817.84 & 3082.01 & 2465.61 & 2465.61 & 2465.61 \\
\hline Sulfatos (mg/L) & 65.67 & 49.00 & 41.33 & 63.67 & 31.33 & 71.00 & 66.00 \\
\hline
\end{tabular}

Fuente: Elaboración propia.

Con base en lo expuesto, también se realizó el análisis de alternativas de las potenciales estructuras hidráulicas. En la actualidad existe dos lagunas de oxidación que trataban anteriormente las aguas residuales de origen domestico provenientes del sector de Monagrillo y de La Villa de Los Santos, pero el manejo de estas lagunas no ha sido el óptimo, por lo que actualmente las aguas residuales que llegan a estos sistemas están bombeadas a la nueva PTAR para su tratamiento. Por lo tanto, con el fin de tener un mayor beneficio de las estructuras hidráulicas existentes, se consideró en el diseño conceptual de la investigación proponer para la adecuación de aguas residuales postratadas provenientes de la PTAR estas lagunas de oxidación, aprovechando así su disponibilidad para la instalación en ellas 
de los humedales artificiales. De esta manera, ambas lagunas servirían para la creación de los humedales referidos, ya que las mismas quedaron sin uso al instalarse en sus predios las estaciones de bombeo del nuevo sistema de alcantarillado, que envían las aguas recolectadas de las comunidades de Monagrillo y La Villa de Los Santos a la Planta de Tratamiento de Aguas Residuales (Figura 13).

Figura 13. Diseño conceptual del mecanismo de adecuación de los efluentes de la PTAR para su posterior uso en riego y recarga de acuíferos

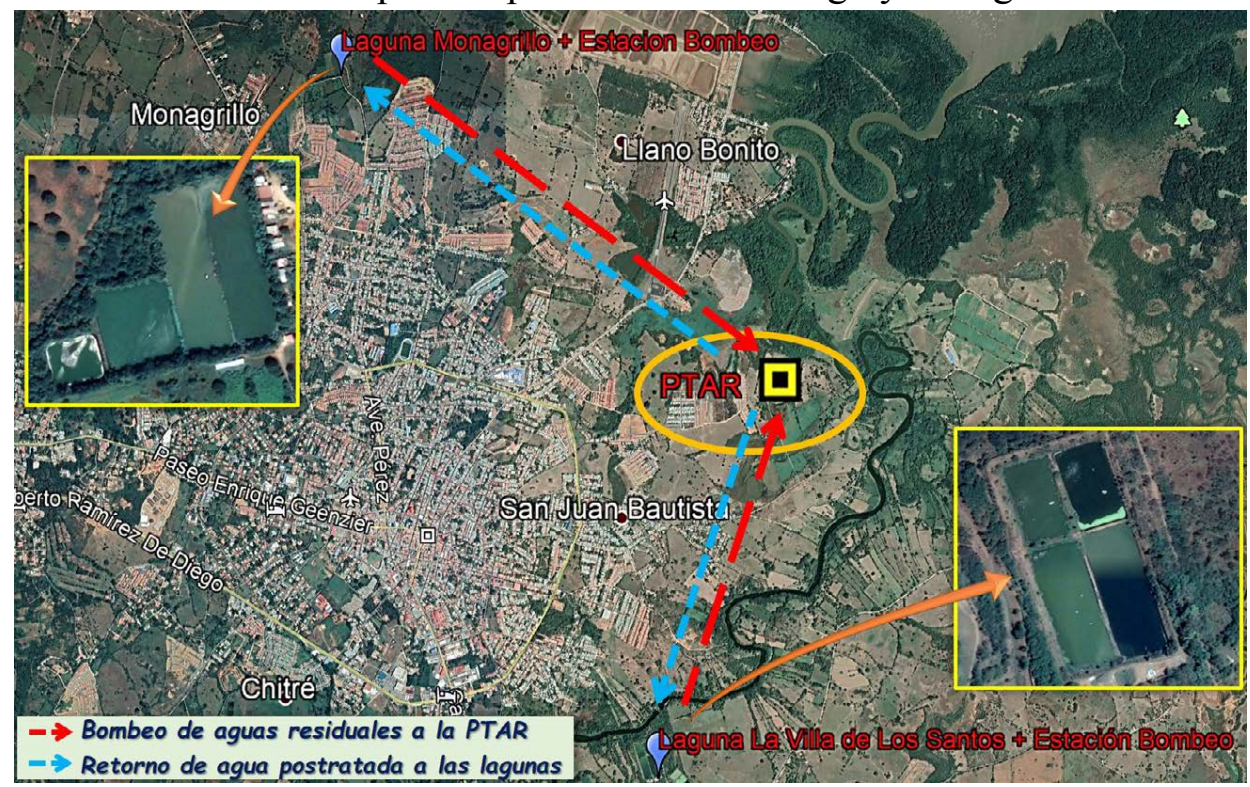

Fuente: Elaboración propia.

Las características técnicas de cada laguna son las siguientes: Laguna de Monagrillo tiene un área estimada de $29,000 \mathrm{~m}^{2}$, con una capacidad de recibir hasta 8 millones de galones de agua postratada y se ubica a $4 \mathrm{~km}$ (aéreos) de la PTAR. Mientras tanto, la laguna de La Villa de Los Santos tiene un área de $34,000 \mathrm{~m}^{2}$, puede albergar 9 millones de agua para su afino y está a unos $3 \mathrm{~km}$ de la planta de tratamiento. 


\section{Definición de la zona de recarga del acuífero y determinación de su capacidad de almacenamiento de caudales infiltrados}

Los trabajos de investigaciones de campo tales como exploraciones geológicas, geofísicas e hidrogeológicas del área estudiada fueron desarrollados en dos etapas, cumpliendo con el principio de las aproximaciones sucesivas. En la Etapa I se realizó la investigación en un área de 160 $\mathrm{km}^{2}$. Luego, en la Etapa II, aplicando el mismo principio metodológico, se realizó un estudio geológico y geofísico en detalle en un área de $16 \mathrm{~km}^{2}$, con el fin de aumentar la densidad de información sobre las condiciones geológicas del subsuelo en la parte baja de la cuenca del río La Villa, generada durante la primera etapa de la ejecución general del proyecto. Esto permitió dar mayor grado de certeza en la planificación de las obras de desarrollo previstas. La información que se obtuvo como resultado de las investigaciones mencionadas ha sido relevante para establecer en la zona estudiada el dimensionado de reservorios subterráneos capaces de admitir, almacenar y entregar aguas, los cuales pueden ser objeto de la técnica de aumentar las reservas hídricas mediante procesos de recarga de acuíferos por excedentes de riego.

Ante la necesidad de formar una imagen tridimensional del bloque modelo litológico que conforma el área de investigación, inicialmente en la Etapa I se realizó la exploración geofísica a través de la ejecución de 18 Sondeos Eléctricos Verticales (SEV), apoyada por el análisis de los mapas geológicos e hidrogeológicos de la zona, así como por las observaciones de campo ejecutadas durante el levantamiento geológico, revelándose la estructura del reservorio subterráneo. Mientras tanto, en la Etapa II, con el fin de delimitar la estructura perspectiva para la recarga y definir la disposición de las capas geológicas, fueron ejecutados 10 sondeos geoeléctricos adicionales a los realizados en la Etapa I, lo que permitió añadir a la información preexistente del proyecto un mayor grado de detalle (Figura 14). Los nuevos SEV de la Etapa II se distribuyeron de manera tal que fuera posible la estructuración de un bloque modelo geológico ampliado, con el fin de poder conocer las condiciones hidrogeológicas del área de influencia del proyecto y así determinar el comportamiento del flujo de las aguas subterráneas en la zona acuífera ante una eventual recarga de esta zona acuífera por riego agrícola. 
Valentina Opolenko

Potencialidad de uso de aguas servidas para riego y recarga de acuiferos: cuenca del río La Villa,

República de Panamá

Los estudios realizados en la Etapa II, al igual que en la Etapa I, dieron como resultado la generación del bloque modelo a escala de la disposición espacial de las capas litológicas, o bien, los tipos de roca que componen el subsuelo, así como los mapas y perfiles geológicos asociados al área de emplazamiento del proyecto (Figura 15).

La descripción y caracterización geológica facilitó una correcta comprensión de la geometría de los materiales litológicos que conforman zonas acuíferas en el área de influencia de potencial recarga. Los datos obtenidos de litología, que fueron interpretados de los SEV, se integraron a un bloque modelo con el uso del software RockWorks, donde se consolidó la información litológica de nuevos SEV y
Figura 14. Localización de los Sondeos Eléctricos Verticales (SEV) realizados en las Etapas I y II en la parte baja de la cuenca del río La Villa
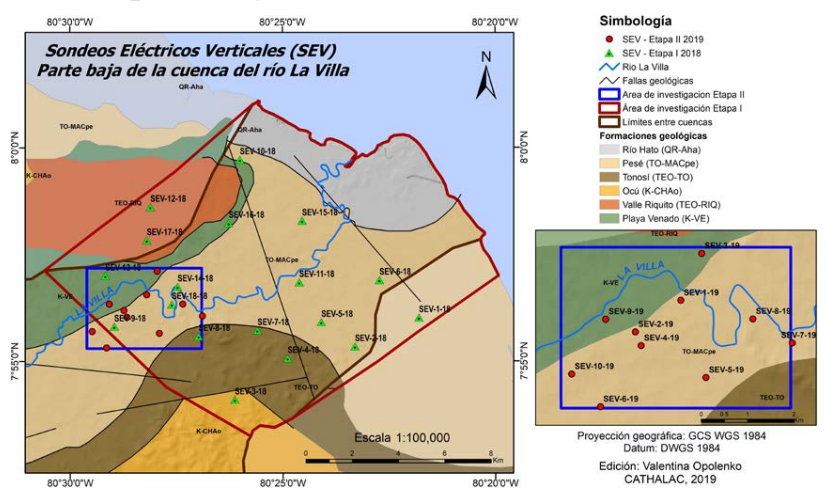

Fuente: Elaboración propia.

Figura 15. Bloque modelo (a) y diagrama de cercas (b) del área de investigación, Etapa II
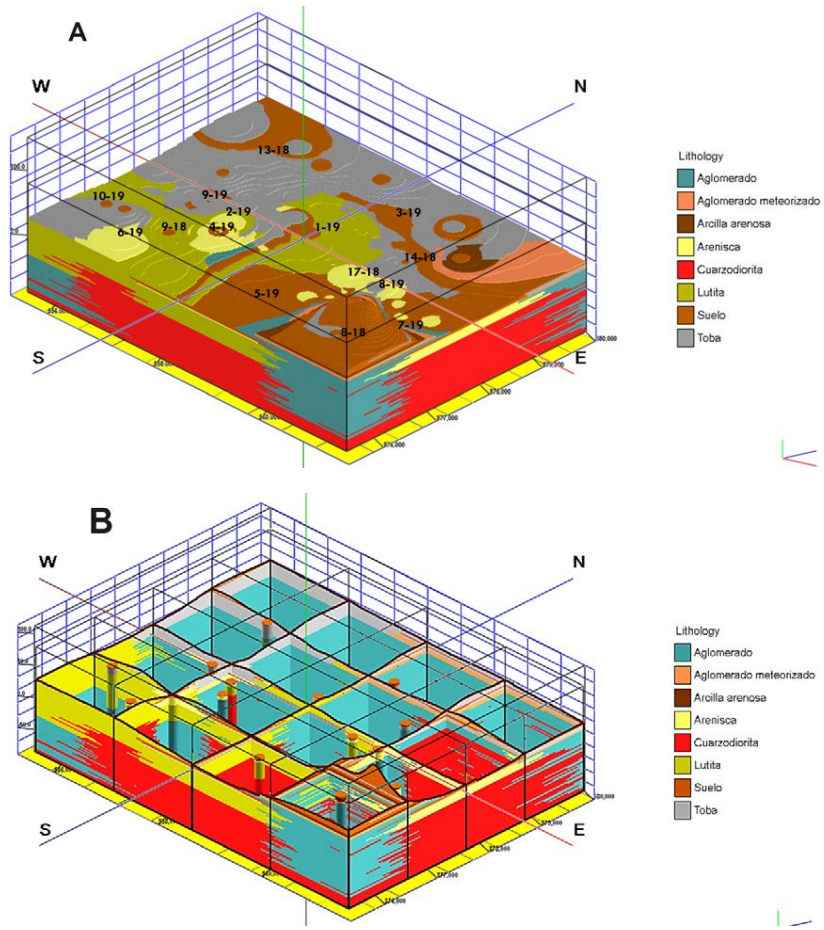

Fuente: Elaboración propia. 
una parte de preexistentes de la Etapa I. Este importante resultado facilitó analizar por simple inspección la disposición espacial de los diferentes materiales que componen el territorio estudiado.

Del análisis de bloque modelo (Figura 15a) se obtuvieron los cálculos volumétricos de las distintas capas litológicas, lo que permitió estimar las reservas de agua subterránea que eventualmente pueden almacenarse a través de las propiedades, así como la porosidad eficaz de las rocas. La vista en perspectiva y en tres dimensiones de cada capa litológica en particular, aislada del resto en su conjunto, permite comprobar el rol de cada una en los complejos procesos de deposición de las aguas subterráneas, dándole a esta investigación un carácter de genuinos aportes inéditos al conocimiento científico del área.

De esta manera, se logró establecer del bloque modelo la base o el piso impermeable, conformado por cuarzodiorita de la formación Valle Riquito, que confina el posible reservorio subterráneo, idóneo para recibir los aportes de la recarga, así como almacenarla. También, se definió la capa de aglomerado fracturado (Formación Playa Venado), que se reveló por sus características y dimensiones como el acuífero principal, con una permeabilidad secundaria originada por las fisuras, con la capacidad de recibir, de acuerdo con su porosidad, un volumen de agua de $1.45 \mathrm{~km}^{3}$. La capa de arenisca (Formación Pesé), fue identificada como la segunda capa en importancia por sus propiedades de porosidad (Figura 16). 
Valentina Opolenko

Potencialidad de uso de aguas servidas para riego y recarga de acuíferos: cuenca del río La Villa, República de Panamá

Figura 16. Caracterización de principales capas litológicas: (a) cuarzodiorita, (b) aglomerado y (c) arenisca, que reflejan la magnitud de un perspectivo reservorio acuífero
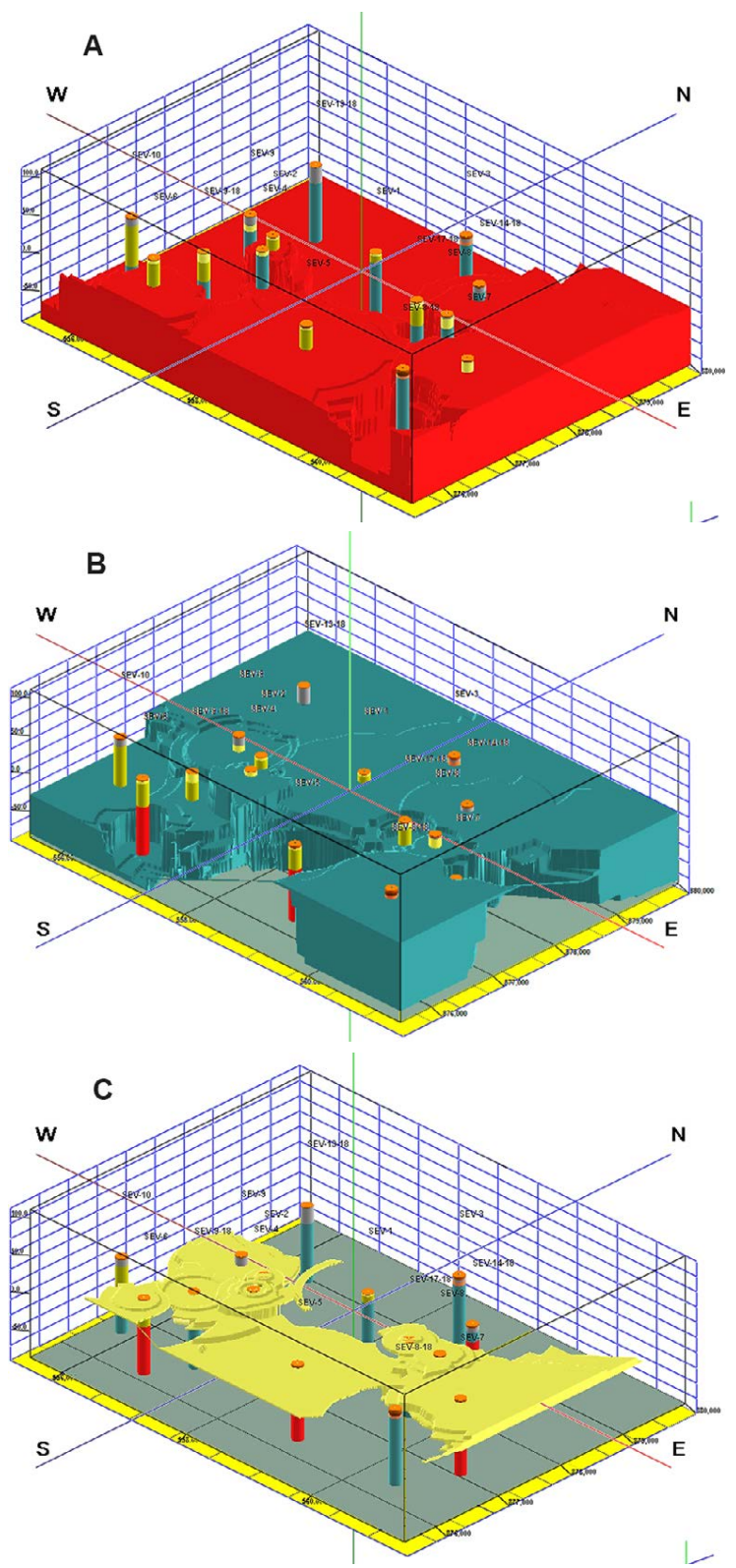

Fuente: Elaboración propia. 
Además de la exploración geológica, se desarrolló en ambas etapas del proyecto el estudio hidrogeológico que proporcionó un conocimiento adecuado del acuífero a recargar, de sus propiedades hidrogeológicas y características hidráulicas, teniendo en cuenta las condiciones geológicas que permitieron determinar la dirección de flujo de aguas subterráneas (Figura 17), así como el flujo de las aguas de recarga desde la superficie a la zona saturada.

Figura 17. Mapa de elevación (en metros) de la mesa freática del área de estudio (Etapa I)

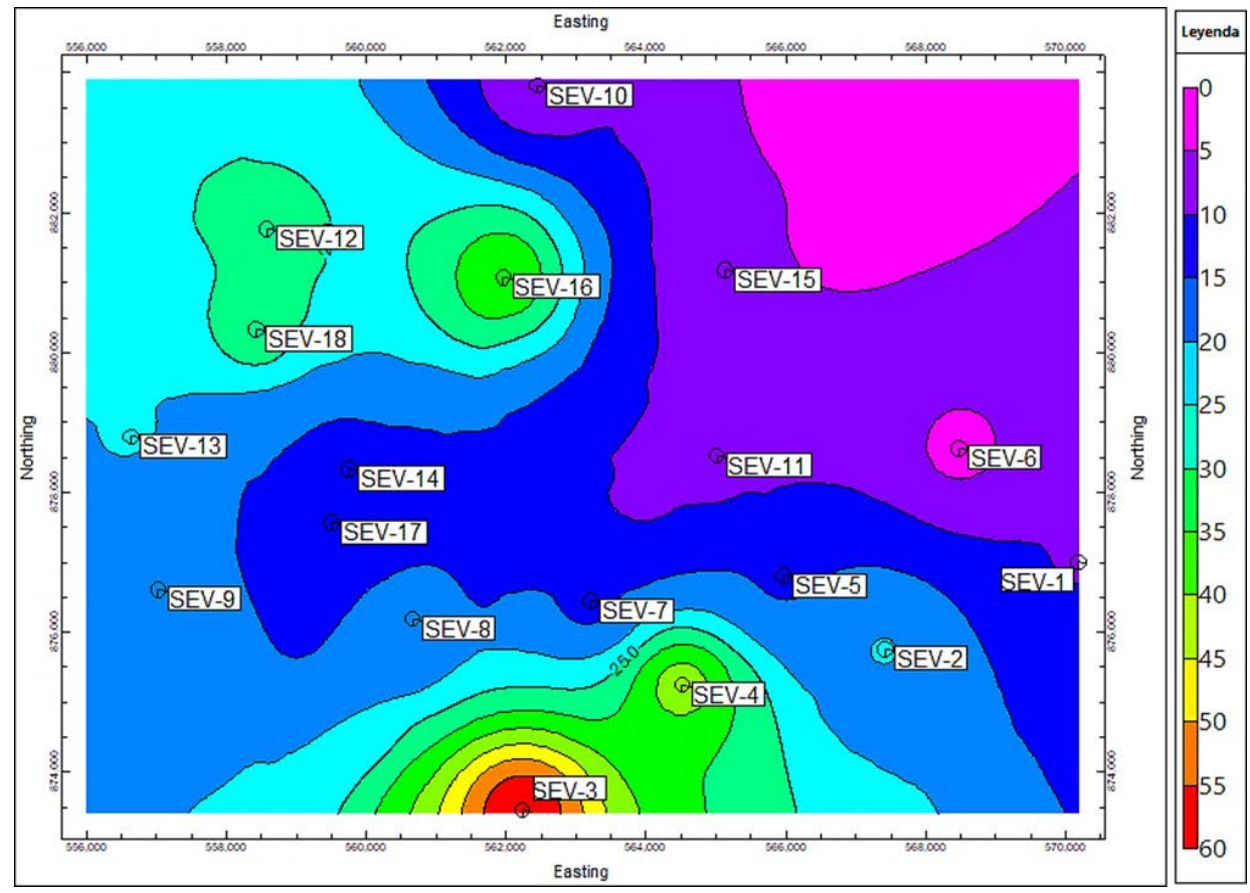

Fuente: Elaboración propia. 
Potencialidad de uso de aguas servidas para riego y recarga de acuíferos: cuenca del río La Villa, República de Panamá

Durante la ejecución del proyecto se realizaron 27 ensayos hidráulicos de Doble Anillo e igual cantidad del método Porchet, 17 en la Etapa I y 10 en la Etapa II (Figura 18).

Figura 18. Localización de los ensayos de infiltración y permeabilidad en las Etapas I y II
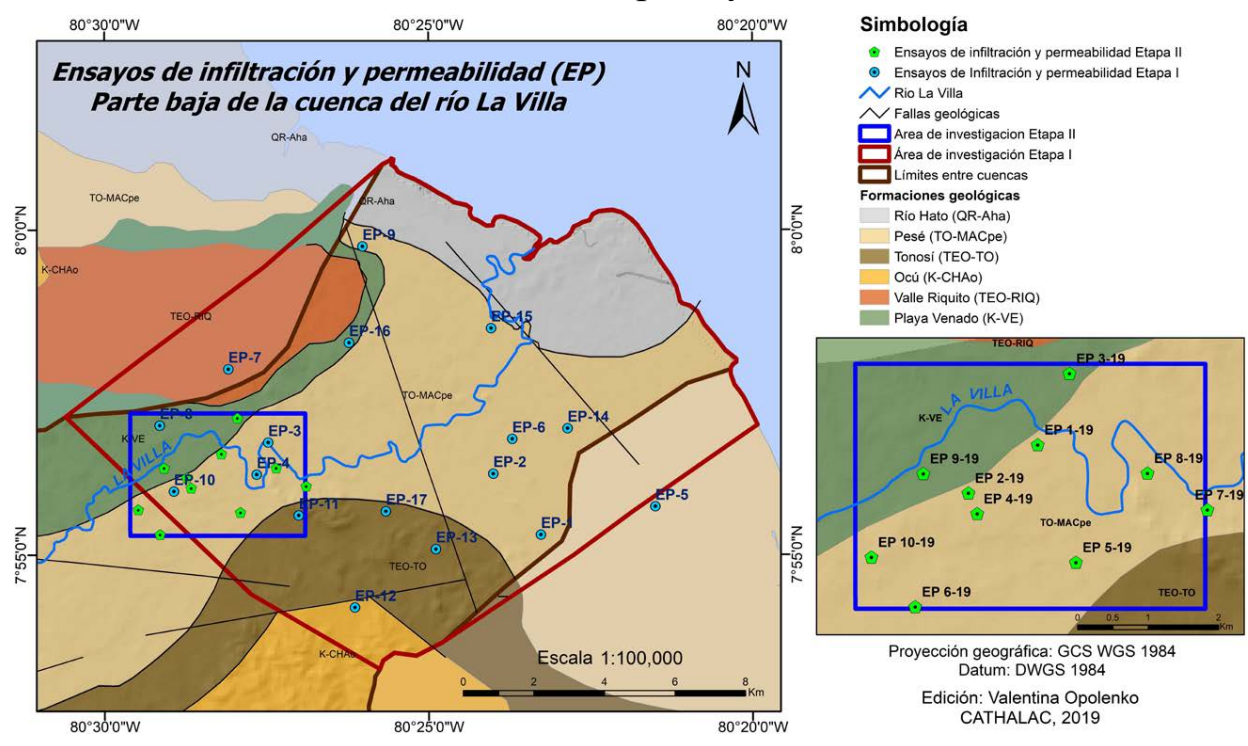

Fuente: Elaboración propia.

Una de las características físicas principales del acuífero que determinan su viabilidad para recibir, almacenar y, posteriormente, recuperar el agua, es la conductividad hidráulica. Los datos obtenidos durante el desarrollo del proyecto dieron como resultado una permeabilidad promedio de $\mathrm{K}=1.07 \mathrm{~m} /$ día para el área de estudio, clasificada según "Clases de Terrenos de Bredding" como muy pequeña (Custodio \& Llamas, 1976), pero desde el punto de vista de recarga de acuíferos, el valor obtenido de conductividad hidráulica se considera como una "Conductividad Hidráulica idónea", ya que se encuentra en el rango de 100 y $0.1 \mathrm{~m} /$ día (Guimera-Sola, 2014). Como resultado final, una vez definidas las características geológicas y las condiciones hidrogeológicas del área investigada, se estimó que de los distintos métodos existentes de recarga artificial de acuíferos, el método de recarga superficial por excedentes de riego, que consiste en aplicar el agua en campos de extensión (dispositivo 
de infiltración), buscando una gran superficie de contacto agua-terreno, que se logra normalmente mediante el riego durante la estación seca, es el método más viable a utilizar en la parte baja de la cuenca del río La Villa desde el punto de vista técnico, económico, así como social.

\section{Conclusiones}

A partir de los resultados obtenidos en la presente investigación, se puede concluir que durante el desarrollo del proyecto fue posible comprobar el eventual uso de agua regenerada procedente de la Planta de Tratamiento de Aguas Residuales (PTAR) en agricultura, como una opción que se estuvo estudiando. Otro aspecto abordado, además de uso de agua regenerada para riego, ha sido establecer la viabilidad técnica de la potencial recarga artificial de acuíferos y definir el método más adecuado para este fin. Estos objetivos se lograron plenamente al poder caracterizar los efluentes de la planta depuradora y su capacidad de reúso, estableciendo el método de afino y potencialidades de almacenamiento, con la instalación en los predios de la PTAR de un sistema experimental con humedales artificiales tipo horizontales subsuperficiales, en los cuales se concretó el tipo de vegetación que se utilizaría para mejorar la calidad de agua de descarga. El experimento realizado tuvo éxito en su desarrollo, ya que permitió, a través de los análisis del efluente retenido en los módulos con fines de mejoras, establecer el nivel de remoción de los contaminantes del agua postratada con la ayuda del sustrato y la vegetación seleccionada, pues el agua afinada podría utilizarse para el riego y recarga de acuíferos.

En este caso específico fueron sembradas en módulos experimentales dos variedades de pasto, tales como el pasto Alemán y pasto Tanner, los cuales fueron seleccionados de entre las 20 especies de pastos y forrajes importantes de Panamá por su fisiología, productividad, valor nutritivo y la mejor adaptación en el área de estudio. Ambas especies dieron como resultado en los análisis bromatológicos realizados a las plantas cortadas después de 45 días de crecimiento en módulos experimentales altos niveles de proteína y digestibilidad. Esto podría representar una utilidad inmediata y económicamente importante para el sector ganadero en el futuro, además del uso de agua regenerada para el riego, cuando se establecerán los humedales en dos lagunas de oxidación existentes y que actualmente se encuentran en desuso. 
También, una vez definidas las características geológicas y las condiciones hidrogeológicas del área investigada, se estimó que de los distintos métodos existentes de recarga artificial de acuíferos, el método de recarga superficial por excedentes de riego, que consiste en aplicar el agua en campos de extensión (dispositivo de infiltración), buscando una gran superficie de contacto agua-terreno, y que se logra normalmente mediante el riego durante la estación seca, es el método más viable a utilizar en la parte baja de la cuenca del río La Villa desde el punto de vista técnico, económico, así como social.

De esta manera, se puede concluir al cumplir con los objetivos planeados que, con la ejecución del presente trabajo investigativo en la cuenca del río La Villa, se entra en una nueva fase de la explotación y gestión responsable del recurso hídrico en la República de Panamá. Los resultados de esta investigación representan un estudio pionero a escala local, en el cual se trata de expresar un esfuerzo por mostrar que las aguas residuales tienen un alto valor y aplicabilidad en la solución de problemas de escasez hídrica, y pueden contribuir a una mayor seguridad alimentaria de la cuenca, impulsando desarrollo socioeconómico y sostenibilidad ambiental. Mediante la utilización controlada y previamente estudiada de los efluentes de la PTAR, se crearán beneficios sociales, económicos y ecosistémicos para los habitantes de la cuenca del río La Villa. Se espera también que, generando conocimiento, se cambiará el concepto que la sociedad en general tiene sobre las aguas residuales y esto se logra a través de la sensibilización, difusión y transferencia científica. Se entiende que el conocimiento científico sobre el uso de las aguas servidas en Panamá no se limita a un solo proyecto, lo que implica la necesidad de nuevas investigaciones en este campo, para que las aguas residuales dejen de ser un recurso desaprovechado.

\section{Agradecimientos}

La autora agradece a las siguientes personas, instituciones y organizaciones que nos acompañaron y brindaron su apoyo a lo largo de esta investigación:

A la Secretaría Nacional de Ciencia, Tecnología e Innovación (SENACYT) y el Programa de Innovación para la Inclusión Social y la Productividad del BID, por su decidida contribución al desarrollo científico-tecnológico de este país. 
Igualmente, al personal de la Dirección Regional de Herrera y Los Santos del Ministerio de Ambiente (MIAMBIENTE); del Ministerio de Desarrollo Agropecuario (MIDA) y del Instituto de Acueductos y Alcantarillados Nacionales (IDAAN).

Al equipo de CATHALAC que de alguna manera apoyó la exitosa ejecución de este proyecto y a los Consultores MSc. Geólogo Roneldo Arjona, el Ing. Agrónomo Josué García y al Investigador MSc. Pablo Martínez de la Universidad Tecnológica de Panamá (UTP), por su valiosa participación y aportes en el desarrollo de esta investigación.

A la Constructora RODSA, S.A., que está a cargo de la Planta de Tratamiento de Aguas Residuales (PTAR) de Chitré, en especial al Ing. José García.

A los Municipios de Chitré y Los Santos, a los miembros del Comité de Cuenca Hidrográfica del río La Villa, y a las distintas comunidades beneficiarias por su actitud positiva y aporte de conocimiento local.

\section{Referencias}

Autoridad Nacional del Ambiente. (ANAM, 2008). Plan de Ordenamiento Territorial Ambiental de la cuenca del río La Villa (POTA). Panamá: Autoridad Nacional del Ambiente.

Autoridad Nacional del Ambiente. (ANAM. (2011). El Plan Nacional de Gestión Integrada de los Recursos Hídricos de la República de Panamá (PNGIRH) 2010-2030. Autoridad Nacional del Ambiente (ANAM), República de Panamá. ISBN 978-9962-609-77-3

Casas, A., Tapias, J., De Bustamante, I., De Miguel, A. \& Lillo, J. (2011). Guía metodológica para el uso de aguas regeneradas en riego y recarga de acuíferos. España: Ed. Consolíder Tragua. Gobierno de España.

Cornejo, A., López, E., Ruiz, R., Sedeño, J., Armitage, B., Arefina, T., Nieto, C., Tuñon, A., Molinar, M., Ábrego, T., Pérez, E., Tuñón, A., Magué, J., Rodríguez, A., Pineda, J., Cubilla, J. \& Avila, I. (2017). Diagnóstico de la condición ambiental de los afluentes superficiales de Panamá. Instituto Conmemorativo Gorgas de Estudios de la Salud. Panamá: Ministerio de Ambiente.

Custodio, E. \& Llamas M. R. (1976). Hidrología Subterránea. Tomo I y II. Barcelona: Ediciones Omega, S.A. 
De Bustamante, I., Cabrera, M.C., Echegaray, M., Candela, L., Pérez-Barbón, A. \& Martínez-Hernández, V. (2016). Reutilización de aguas regeneradas en el marco de la planificación hidrológica. Las aguas subterráneas y la planificación hidrológica. Congreso Hispano-Luso sobre las Aguas Subterráneas en el Segundo Ciclo de Planificación Hidrológica. Madrid: Asociación Internacional de Hidrogeólogos (AIH).

Delgadillo, O., Camacho, A., Pérez, L. \& Andrade, M. (2010). Depuración de aguas residuales por medio de humedales artificiales. Cochabamba, Bolivia: Centro Andino para la Gestión y Uso del Agua (Centro AGUA)

Dirección General de Recursos Minerales. (DGRM, 1991). Mapa Geológico de la República de Panamá; Escala 1:250.000. Panamá: Ministerio de Comercio e Industrias., República de Panamá.

Farhad, S. (2012). Los sistemas socioecológicos. Una aproximación conceptual y metodológica. Sevilla, España: Departamento de Economía, Métodos cuantitativos e Historia económica, Universidad Pablo de Olavide.

Food and Agriculture Organization of the United Nations. FAO. (2013). Reutilización del agua en la agricultura: ¿Beneficios para todos? Informe sobre Temas Hídricos $\mathrm{N}^{\circ} 35$ FAO. Organización de las Naciones Unidas para la Alimentación y la Agricultura (FAO), Roma.

Guimera-Sola, J. (2014). Diagnóstico de Metodología para la Presentación y Análisis de Proyectos de Recarga Artificial de Acuiferos. Chile: AMPHOS 21 CONSULTING CHILE LTDA. Ministerio de Obras Públicas.

Instituto Geográfico Nacional "Tommy Guardia”. (IGNTG, 2007). Atlas Nacional de la República de Panamá. Panamá: Instituto Geográfico Nacional "Tommy Guardia".

Instituto Geólogo y Minero de España. (IGME, 2010). Encomienda de gestión para la realización de trabajos científico-técnicos de apoyo a la sostenibilidad y protección de las aguas subterráneas Actividad 8: Selección e identificación de masas de agua donde es preciso plantear estudios y actuaciones de recarga artificial de acuiferos. España: Instituto Geólogo y Minero de España (IGME), Dirección General de Aguas.

Instituto de Investigación Agropecuaria de Panamá. (IDIAP, 2006). Zonificación de suelos de Panamá por niveles de nutrientes. Panamá: Instituto de Investigación Agropecuaria de Panamá. 
Instituto Nacional de Estadística y Censo. (INEC, 2010). XI Censo de Población y VII de Vivienda, 2010. Resultados Finales. Panamá: Instituto Nacional de Estadística y Censo.

Klimentov, P.P. \& Kononov, V.M. (1982). Metodología de las Investigaciones Hidrogeológicas. Moscú: Editorial Mir.

Lara, J. \& Vera, I. (2005). Implantación y evolución de un humedal artificial de flujo subsuperficial en Cogua, Cundinamarca, Colombia. Ingeniería y Universidad, 9(1): 47-63.

Ministerio de Desarrollo Agropecuario. (MIDA, 2009). Resultados de la zonificación Agroecológica de 20 especias de pastos y forrajes en la República de Panamá. Panamá: Secretaría Técnica Programa Nacional de Zonificación Agroecológica, Ministerio de Desarrollo Agropecuario.

Ministerio de Ambiente de Panamá. (MIAMBIENTE, 2019). Oferta y Uso de Agua en Panamá: Basado en los resultados de la Cuenta Ambiental de Agua 2000-2018. Panamá: Dirección de Política Ambiental, Ministerio de Ambiente de Panamá.

Opolenko, V. (2016). Sensibilidad Medioambiental a la desertificación en la cuenca del río La Villa, República de Panamá. (Tesis doctoral). Universidad Internacional de Andalucía y Universidad de Huelva, España.

Peters, M., Franco, L., Schmidt, A. \& Hincapié, B. (2011). Especies forrajeras multipropósito: opciones para productores del trópico Americano. Centro Internacional de Agricultura Tropical (CIAT).

Salas, J., Pidre, J. \& Sánchez, L. (2007). Manual de tecnologías no convencionales para la depuración de aguas residuales: Humedales Artificiales. España: Centro de las Nuevas Tecnologías del Agua (CENTA).

Soil Survey Staff. (1999). Soil taxonomy: A basic system of soil classification for making and interpreting soil surveys. U. S.: Natural Resources Conservation Service. U.S. Department of Agriculture.

United Nations, Department of Economic and Social Affairs, Population Division (UN, 2014). World Urbanization Prospects: The 2014 Revision, Highlights. (ST/ESA/SER.A/352). New York: United Nations. World Water Assessment Programme. (WWAP, 2017). Informe Mundial de las Naciones Unidas sobre el Desarrollo de los Recursos Hidricos 2017. Aguas residuales: El recurso desaprovechado. París: UNESCO. 